Article

\title{
Initial Teacher Education for Inclusive Education: A Bibliometric Analysis of Educational Research
}

\author{
Daniela Maria Cretu $^{1, *(\mathbb{D})}$ and Felicia Morandau ${ }^{2}$ \\ 1 Teacher Education Department, Lucian Blaga University of Sibiu, 34 Calea Dumbravii, \\ 550324 Sibiu, Romania \\ 2 Social Work, Journalism, Public Relations and Sociology Department, Lucian Blaga University of Sibiu, \\ 2A Lucian Blaga, 550169 Sibiu, Romania; felicia.morandau@ulbsibiu.ro \\ * Correspondence: daniela.cretu@ulbsibiu.ro
}

Received: 25 May 2020; Accepted: 15 June 2020; Published: 17 June 2020

\begin{abstract}
In the context of international demands in recent decades to strengthen the commitment to inclusive policy and practices within education systems, teacher education has been challenged to find ways to prepare teachers capable of addressing the various needs of learners. The goal of this paper is to examine the research literature on initial teacher education for inclusive education (ITEIE) by using bibliometric analysis carried out on 440 documents indexed by Web of Science (WoS). The findings support the understanding of the ITEIE field regarding the evolution across time, the contributions in the field, the relevant journals, authors, and papers, the collaboration patterns. Although there has been a significant increase in the number of published works over the years, only a small number of countries and researchers have made significant contributions to the field. The analyses performed with VOSviewer software indicated poor collaboration among participating countries and authors. Several general topics have been addressed in the field over the past 25 years. There is a need to develop more cross-border research groups to ensure progress in the field. By mapping the emerging ITEIE research literature, this study can be a starting point for the development of new studies in the area.
\end{abstract}

Keywords: pre-service teachers; inclusion; teacher education programs; bibliometric analysis; teacher educators; collaboration

\section{Introduction}

An important role in achieving social sustainability can be played by inclusive education (IE) in which every person matters, and teachers are the main agents in the implementation of educational practices likely to support the development of every child or young person. Training teachers to address the diversity of learners and to develop inclusive educational environments for all is relevant and impactful for building a sustainable future, to which individuals learning today in schools or universities should be given a chance to contribute. Teacher educators from different parts of the world make great efforts to empower teachers and future teachers to work within the framework of IE.

Teacher education for IE has become a major focus [1] in the context of intensifying the international policy agenda on IE, which resulted in an increasing diversity of students in mainstream classrooms. For instance, in 1994 the Salamanca Statement stated the access of those with special educational needs to regular schools and called upon the governments to ensure that pre-service and in-service teacher education programs address the issue of special needs education in inclusive schools [2]. The right of persons with disabilities to an IE system at all levels is recognized by the United Nations Convention on the Rights of Persons with Disabilities in 2006, which also emphasizes the need to provide training that supports professionals working at all levels of education with persons with 
disabilities [3]. In 2008, the participants in the UNESCO International Conference on Education agreed on the importance of a wider approach to IE that should cater to the needs of all learners and that can serve as a fundamental principle towards an education for sustainable development and lifelong learning for all. Thus, the role of tertiary education in training preservice teachers and teachers about inclusion was clearly highlighted [4]. In 2015, the 2030 Agenda for Sustainable Development included IE for all as a part of the fourth goal of the 17 announced [5]. The Education 2030 Framework for Action, which provides guidance for the implementation of this goal, argues that inclusive school facilities and teacher training on IE should be regarded as strategies to address exclusion and marginalization [6]. These initiatives and documents with world-wide impact highlight a growing political focus on IE.

The approach of IE from the perspective of teacher education opens two main research lines of analysis: Initial and continuous teacher education for IE. In the present study the focus is on the first research line, i.e., on initial teacher education for inclusive education (ITEIE). How the issue of IE within university programs for initial teacher education is mirrored in educational research is the problem tackled by this paper.

The aim of this paper is to examine the research literature on ITEIE by using bibliometric analysis carried out on the Web of Science (WoS) database. We analyzed 440 documents (articles, proceedings papers, and book chapters) extracted from WoS, covering the period 1996-2020 (April 7). The objectives of the investigation were: To track the development of ITTIE research over time and the distribution of the published documents across countries, organizations, and type of papers; to identify journals, authors, and papers which have influenced the research in the field; to reveal the connections that exist between authors, journals and terms. We used bibliometric indicators offered by WoS and bibliometric methods for mapping the intellectual structure of ITEIE research. The findings helped us to provide an objective and updated overview of ITEIE research. However, it must be acknowledged that an important limitation of the research is related to the fact that in our study were used documents from a single database, namely, WoS. Other databases such as Scopus, Google Scholar, Elsevier Science Direct, etc., contain documents in the analyzed field and could be explored. There is an open path for future research that might integrate multiple databases that index papers on ITEIE.

In the next section, we present an analysis of the scientific literature in the field of ITTIE and lists some bibliometric studies in the field of teacher education, and IE. The third section describes the methodology applied in this study and is followed by the results of the bibliometric and the science mapping analysis. The results section is structured according to the three research questions. The fifth section provides discussions on the study's results and the final section presents conclusions, limitations, and proposals for future research, and theoretical and practical implications.

\section{Literature Analysis}

The calls for IE for all have guided the efforts that many countries have made to render educational policy and practice more inclusive [7]. Perceived as a global movement for at least the last 30 years [8], IE is one of the most significant issues facing the education community both nationally and internationally [9]. Initially associated with the placement of children with disabilities in the regular system, the concept of IE has expanded and evolved, and is now understood by UNESCO as "the process of strengthening the capacity of the education system to reach out to all learners" [10]. However, some authors have drawn attention to the different understanding of the concept in research and practice, which makes the progress in the field problematic [8,11-14]. For example, as a result of the analysis of research on IE, Göransson and Nilholm [11] identified four meanings of the inclusion: (1) As the placement of pupils with disabilities in mainstream classrooms; (2) as meeting the social/academic needs of pupils with disabilities; (3) as meeting the social/academic needs of all pupils; (4) as creation of communities. Krischler et al. [13] consider that this conceptual variety explains the inconsistent implementation of IE and reflects on teacher training programs in which the next generations of teachers are educated. In the context of this study, IE is understood in its broad sense, as providing learning opportunities for all students, including those with disabilities, immigrants, ethnic minorities, etc. 
Despite this diversity of approaches to IE (which are not, however, the focus of this study, but cannot be neglected either), one thing is certain: If IE is a problem related to general education and regular schools, then all the teachers should be involved in this process. In the successful implementation of inclusive practices, generalist teachers are seen as having an important role [15]. This does not exclude the support received from special education teachers when needed. The regular school teachers are core actors in developing inclusive practices and they need to learn to meet the needs of a diverse range of learners effectively, including those with special educational needs and disabilities. This has major implications in the sense of preparation of all teachers in this direction and higher education institutions delivering teacher education programs are seen as being responsible for this aspect [16]. The importance of teacher education for the development of inclusive educational systems cannot be contested [17]. Therefore, teacher education programs are expected to equip future teachers with the necessary knowledge, skills, attitudes, and values to teach diverse student populations and meet the diverse needs of different categories of learners [4].

Considering this real need, over the last decades many teacher education programs have gone through a reform process, in terms of structure and curriculum in order to find better ways to prepare teachers for the demands of IE. Teacher educators have been challenged to reflect on how IE can be addressed as an essential element of teacher training, to implement curricular approaches embedded with different aspects of IE or even to develop their own skills in the field to train future teachers. Teacher educators have an important role in ensuring that teacher education programs help prospective teachers to respond wisely to diversity [18]. Their initiatives and efforts have generated research papers and projects focused on issues related to teacher training for IE. In a recent editorial material, Florian and Camedda [19] highlighted the increase in the number of research or projects addressing teacher education for IE and noted their evolution from the inclusion of learners with special educational needs towards broader issues of social inclusion associated with migration, mobility, language, ethnicity, and intergenerational poverty.

As the first and crucial phase in a longer and dynamic process of professional development, initial teacher education lays the foundation for inclusive approaches in education, in terms of fostering knowledge, skills, attitudes, and values that pre-service teachers need to become inclusive educators that enhance learning in all pupils. Florian and Rouse argued that "the task of initial teacher education is to prepare people to enter a profession which accepts individual and collective responsibility for improving the learning and participation of all children" [20] (p. 596). This foundation should be strong enough, so that in time, pre-service teachers can develop competences required for inclusive teaching [17]. Naturally, it is necessary to invest further efforts in the continuous professional development of teachers in what concerns IE aspects.

As a field of information science that studies bibliographic material quantitatively, bibliometrics is very useful in organizing available knowledge within a specific scientific discipline [21], in evaluating international scientific work in a reliable, transparent, and objective manner, and in creating maps for scientific domains [22]. The use of the bibliometric analysis is growing rapidly, especially in some research fields, such as innovation, entrepreneurship, etc. [23]. In the domain of education, there are a number of bibliometric studies. For instance, in the field of teacher education, we identified some works focusing on various aspects such as foreign language teaching [24], teacher education research [25-27], classroom dialogue [28], digital competence of future teachers [29], teachers' motivation [30], etc. In IE, there are few bibliometric works that address issues such as the research in the field, either globally [31,32] or nationally [33,34], the use of technology in response to diversity [35], etc. For instance, in a very recent bibliometric study [31], the authors mapped the research on IE over the past 25 years, and identified the topic of interest to us, the pre-service teacher education and their attitude toward IE, as one of the general themes addressed in IE literature, alongside others such as: IE in higher education settings, teaching for inclusion and in-service professional development on IE, and practices and principles of IE. All these bibliometric studies are published in recent years, more precisely between 
2015 and 2020, which confirms the idea that the analysis of a large amount of data (what is called Big Data) has acquired great popularity in the last decade [36].

There are review studies in the field which examine issues such as research regarding teacher training for IE [37], initial teacher education for inclusion [38], research findings on ADHD with relevance for teachers, teacher educators and IE [39], the use of augmented reality in IE [40], pre-service teachers' attitudes towards inclusion [41], inclusive pedagogy in physical education [42], and teacher training programs for the inclusion of students with special education needs in regular primary schools [43]. Review studies are valuable in providing experts' evaluation on the literature in a field, but as an alternative approach, bibliometric studies are objective and reliable resources that offer a mapping of a research field, allowing for a much wider coverage of selected studies [31].

In order to gain insights into the development of ITEIE, we opted for a bibliometric approach to it. To achieve the goal, we will look for answers to the following research questions:

RQ1: What is the volume and distribution (countries, organizations, and type of papers) of scientific research in ITEIE?

RQ2: What are the most influential journals, authors, and papers in ITEIE?

RQ3: What are the collaboration patterns in ITEIE and the connections existing between authors, journals, and terms?

As far as we know, this is the first study that addresses this line of research (ITEIE) from a bibliometric approach. We have not identified bibliometric studies that connect the two fields, teacher education, and IE addressing issues related to inclusive education in teacher education. Thus, we fill in a gap and open the perspective for future studies. By providing an objective and up-to-date overview on ITEIE literature based on bibliometric and visualization analysis, we meet the need of researchers, teacher educators, and practitioners to be well-informed and documented and even to develop ideas for their future research.

\section{Methods}

\subsection{Search Strategy}

In accordance with the goal of the present study, a systematic search was carried out in WoS Core Collection database, which includes high quality scientific and scholarly research in over 250 science, social sciences, and humanities disciplines. WoS is an authoritative source for researchers and one of the main sources for citation data [44], an important source of scientific documentation for bibliometric analysis [22]. In our search strategy, we followed PRISMA (Preferred Reporting Items for Systematic Reviews and Meta-Analyses) guidelines for conducting reviews of research [45]. The five-step procedure for conducting science mapping research (research design; compilation of bibliometric data; analysis; visualization; interpretation) recommended by Zupic and Cater [23] guided our investigation, too.

The initial search focused on two major fields: Teacher education and inclusive education. In order to identify research papers for the two fields, we carried out an advanced search. This kind of search permits the forming and combination search sets. We used field tag (TS = Topic), which helped us search for specific terms within a record: Title, abstract, author keywords, and keywords plus. Two key queries were used to identify papers related to ITEIE: (1) TS $=($ "pre-service teacher*" OR "preservice teacher" OR "teacher* candidate*" OR "initial teacher* education*" OR "initial teacher* training*" OR "student* teacher" OR "future teacher" ${ }^{*}$ OR "prospective teacher" OR "preservice teacher* education*" OR "pre-service teacher* education*"); (2) TS = ("inclusive education" OR "inclusive pedagog*" OR "inclusive practic*" OR "special education* need" OR "disabilit" OR "inclusive school $^{* \prime}$ OR "inclusive classroom" ${ }^{*}$ OR "different education* need"). We used Boolean operator, OR in each query based on key terms, a wildcard symbol $(*)$, which represents any group of characters, including no character. For instance, teacher* matches teacher or teachers. We obtained two data sets: $(\# 1=24197 ; \# 2=265254)$, which were then combined by using another Boolean operator, 
AND (\#1AND \#2). As a result, 828 documents were identified. It is worth mentioning here that we did not specify a start date for the publication of the documents. This allowed us to identify all documents indexed on WoS, starting with the earliest paper in the field, to the date of this search process, 7 April 2020.

Then, WoS filters such as document type and research area were used to select the documents. Of the 6 types of documents identified, we restricted our query to articles, proceedings papers, book chapters. We did not include reviews documents $(n=13)$, because they do not constitute primary sources and do not report new information on a subject. Editorial materials $(n=8)$, which usually include editor's views and policies on an issue, and meeting abstracts $(n=7)$ were also excluded. In total, the number of these three types of excluded documents was quite small $(n=28)$. As research area, we only considered documents that belong to the education and educational research field, because the aspects related to the training of future teachers are found mainly in this area. Other research areas were excluded, such as: Rehabilitation, psychiatry, computer sciences, healthcare service sciences, etc. After these WoS filters were applied, the database was reduced to 664 documents. Table 1 presents the inclusion criteria used.

Table 1. Inclusion criteria.

\begin{tabular}{cc}
\hline Criteria & Details \\
\hline Database & WoS Core Collection \\
Topic & ITEIE \\
Document type & Articles, book chapters, proceedings papers \\
Research area & Education and educational research \\
Document contents & Theoretical and empirical studies related to inclusive education in the \\
& initial teacher training at university level \\
\hline
\end{tabular}

Next, the titles, the abstracts and the keywords in the remaining 664 studies were manually examined and assessed for eligibility. The two authors reviewed and assessed independently for eligibility all selected papers. The results obtained were then compared, and all disagreements were resolved through discussion until a consensus was reached. We selected and included in our database theoretical and empirical studies related to IE in the context of different university-based initial teacher education programs. Two hundred and twenty-four irrelevant documents were excluded because: (a) They addressed issues regarding the training of special education pre-service teachers; (b) they included as participants teachers at different points in their continuous professional development (in-service teacher training); (c) they included as participants students with special needs or their parents/school administrators without being directly related to the initial training of teachers. As a result, the final database included a sample of 440 documents (Figure 1). All these documents were finally selected and saved in a marked list on WoS database. 


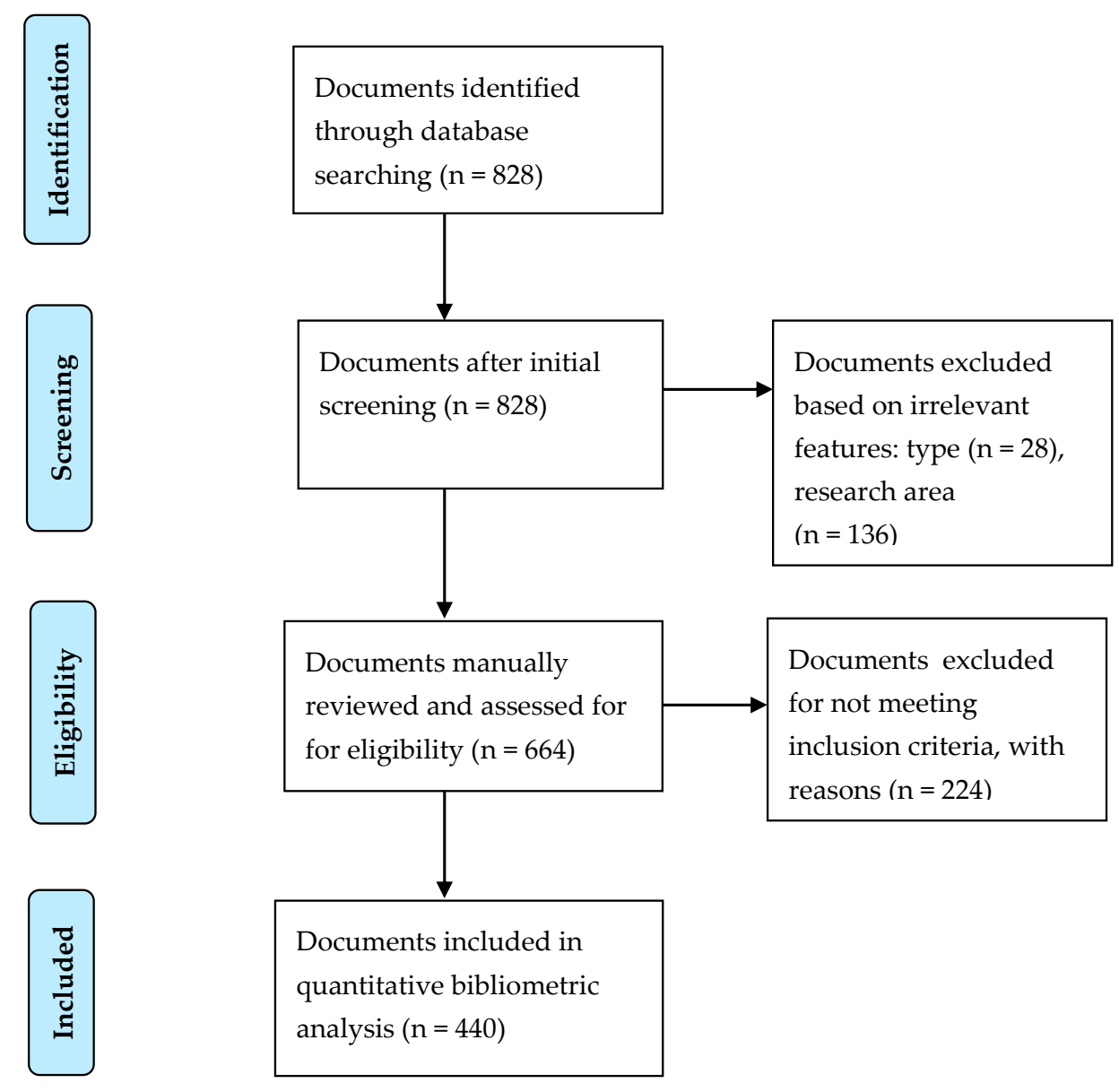

Figure 1. PRISMA diagram describing the collection, the selection, and the inclusion of documents from WoS.

\subsection{Data Analysis}

In order to present the evolution of ITEIE scientific research, we used descriptive statistics based on WoS analytical tools. We carried out bibliometric analyses based on a series of criteria, such as the number of publications over the years, the contributing countries and organizations, the type of documents, the target journals for the publication of the articles, top-cited articles, and authors relevant in the field. The documents in the marked list were then exported in VOSviewer software, version 1.1.14 [46], which was used for creating and visualizing bibliometric networks in the ITEIE knowledge base. Using this software, bibliometric analysis based on co-authorship, co-citation, and co-occurrence of keywords and terms were performed. Co-authorship analysis offers evidence of collaboration at author and country levels. Items (author or country) that are co-authors of a paper are connected through links that reveal the intellectual structure of a field. Co-citation analysis connects items that appear in the same reference list. The cited items (authors or journals) that appear together multiple times suggest related content. Co-occurrences of keywords and terms or co-words connect terms that appear together in the same keyword list, title, or abstract. This analysis helps us build a conceptual structure of the scientific field [23]. The units of analysis (items) are represented on a map as circular nodes. Related nodes are connected by lines, which are named links [47].

\section{Results}

This section comprises the results of the bibliometric analysis in accordance with the research questions. First, we present a survey on the literature in ITEIE focusing on its evolution across time, and the contributions in the field by countries, organizations, document type. Second, we examine 
the most influential journals, the leading authors, and cited papers on ITEIE scientific work. Third, we look at the analysis of the collaboration pattern between authors and countries using co-authorship analysis, at the connections/relationships existing between authors or journals using co-citation analysis, and between terms or keywords using co-word analysis.

\subsection{RQ1: What IS the Volume and Distribution (Countries, Organizations, and type of Papers) of Scientific} Research in ITEIE?

\subsubsection{The Volume of ITEIE Research}

The first works identified are from 1996. The longitudinal analysis for almost 25 years shows that ITEIE knowledge increased over time, but at a different pace. So, three stages can be identified (see Figure 2):

- An early stage, from 1996 to 2007, when 26 documents were published, representing $8.78 \%$ of the total number;

- a moderate growth stage from 2008 to 2014, when 120 papers were published, which accounts for $27.27 \%$ of the total amount. The number of publications increased by over four times compared to the previous period;

- a high growth stage from 2015 to 2020, when 294 scientific papers were published. These represent $66.81 \%$ of the total amount. The number of publications has increased by two and a half times compared to the previous period. Most publications were registered in $2019(\mathrm{n}=74)$. The lower number of publications in 2020 is explained by the fact that only the works indexed on WoS until the date of the search presented in this study were considered (7 April 2020).

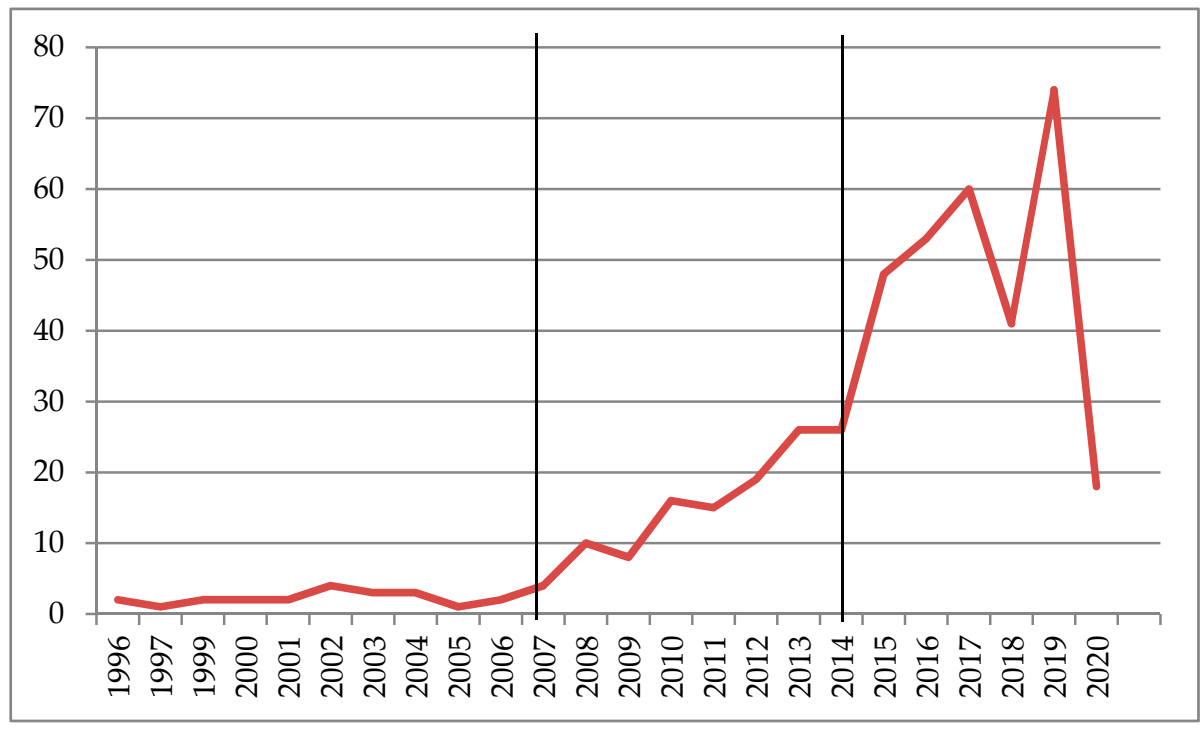

Figure 2. The variation in annual publications number in WoS of the initial teacher education for inclusive education (ITEIE) documents.

If we consider periods of 10 years, the increase is obvious: 20 documents were published between 1996-2005, and 174 between 2006-2015. This growth follows Price's law, according to which the scientific literature tends to double at an interval of 10 years [48]. Moreover, if we consider as a basis the first 10 years (1996-2005) with the 20 documents, we could see that the literature doubled in 5 years, respectively between 2006-2010 (when 40 documents were identified), then doubled in the next 4 years, between 2011-2014 (when 86 documents were registered). In the next three years (2015-2017), the number of documents doubled again (161 documents were published). The trend is clear: Research literature doubles at shorter and shorter periods. Based on these data, we estimate that 
the scientific productivity in the ITTIE field will increase in the following years as well, and the growth rate is higher and higher.

\subsubsection{Distribution across Countries}

Contributions to the literature in ITEIE have come from scholars located in 65 countries. The most active countries that contributed to the development of ITEIE scientific production are presented in Figure 3, with the United States ranked in the first place. Almost a third of the publications in the field come from US authors (144 documents-32.72\%). Important contributions in the field are also made by authors from Australia (54 documents-12.27\%) and Spain (48 documents-10.90\%). Authors from these three countries (USA, Australia, and Spain) have produced $55.89 \%$ of the ITEIE literature. Other countries have also contributed to the literature: Canada (31 papers-7.04\%), England (29 papers-6.59\%), China (16 papers-3.63\%), South Africa (14 papers-3.18\%), Germany (14 papers-3.18\%), Turkey (11 papers-2.5\%), etc.

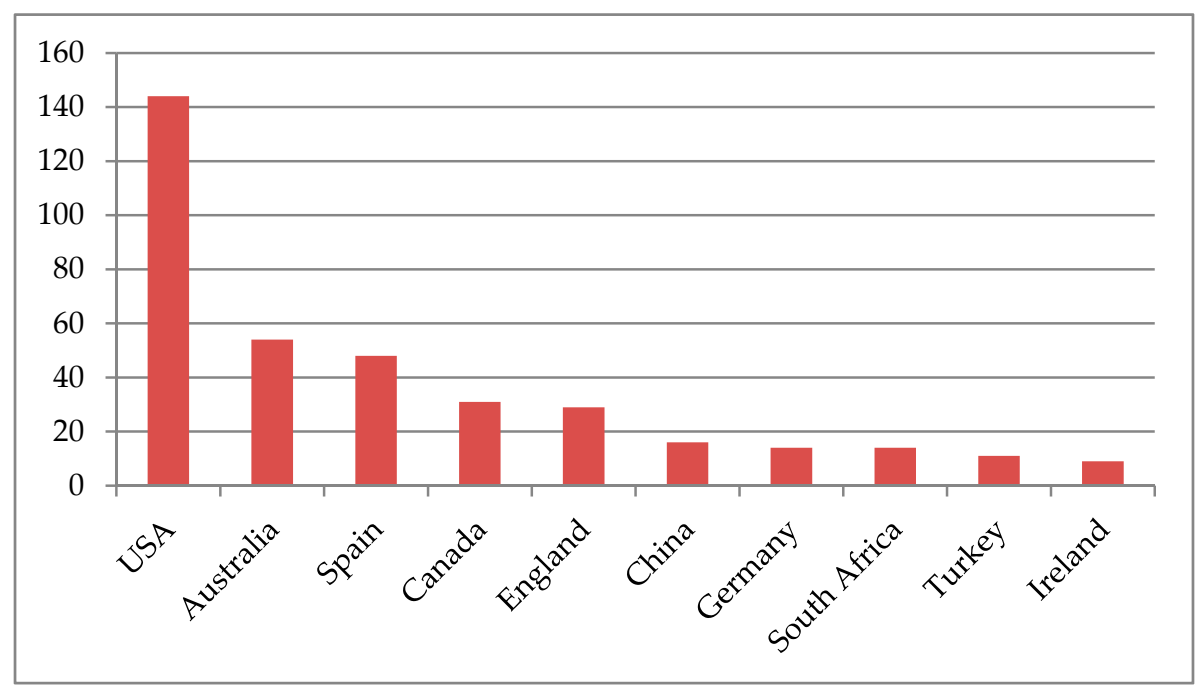

Figure 3. The top contributing countries to the production of ITEIE scientific literature by the number of works.

\subsubsection{Distribution across Organizations}

More than 500 organizations that have contributed to the literature on ITEIE were identified. The most prolific institution in the field is Monash University, with 16 papers, accounting for $3.63 \%$ of all publications. It is followed by University of Valencia (10 papers, $2.27 \%$ ), Education University of Hong Kong with 9 papers $(2.04 \%)$, and University of Virginia also with 9 papers $(2.04 \%)$. Other universities active in the field are University of North Carolina with 8 papers (1.81\%), California State University, Northern Illinois University, Queensland University of Technology (QUT), University of Córdoba, and State University System of Florida, with 7 papers each. These 10 institutions generated $19.74 \%$ of the total number of documents.

\subsubsection{Distribution by Document Types}

Given the three types of documents considered in this study, their distribution is as follows: Articles $(n=389)$ with $88 \%$ of the total number of publications, proceeding papers $(n=34)$ with $8 \%$, and book chapters $(n=17)$ with $4 \%$ (Figure 4$)$. 


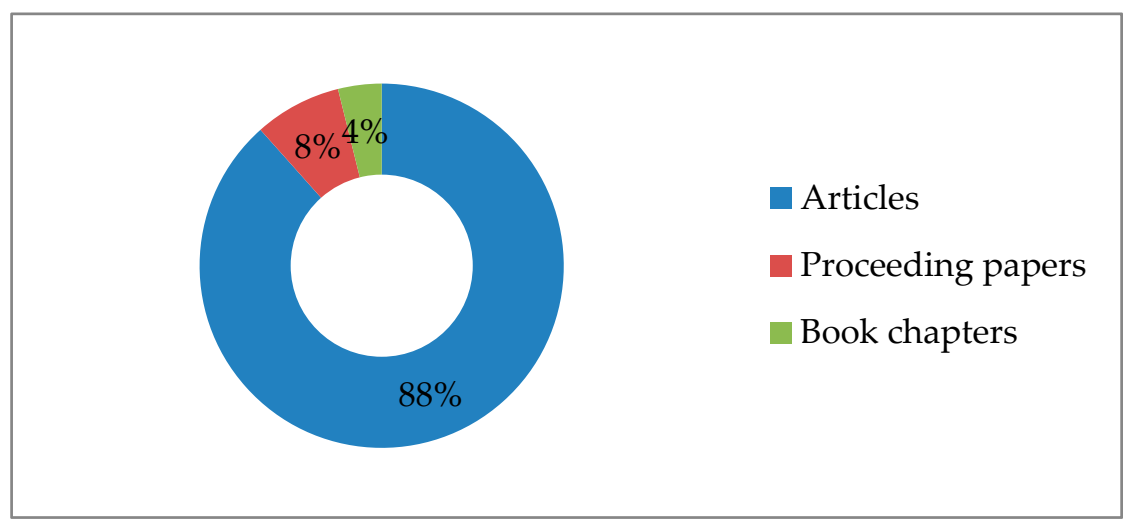

Figure 4. Document types in ITEIE-focused research extracted from Web of Science (WoS).

These three types of documents are written in several languages. Most publications ( $n=392)$, representing $89.09 \%$ of the total number, are written in English. The remaining documents are written in six other languages: Spanish $(n=32,7.27 \%)$, Portuguese $(n=6,1.34 \%)$, Russian $(n=4,0.90 \%)$, German $(n=3,0.68 \%)$, French $(n=2,0.45 \%)$, and Turkish $(n=1,0.22 \%)$. Even if they are written in different languages, all these documents have the title, abstract, and keyword written in English, which is why they were included in the bibliometric analysis conducted in this study. However, it is obvious that English is the most used language for writing and communicating research results in the field.

The documents (articles, book chapters, and proceeding papers) reflect a thematic and methodological diversity that can be grouped in several distinct categories:

- By nature of studies (source of knowledge): Theoretical studies and empirical studies;

- by type of research design and methods of inquiry: Qualitative, quantitative, mixed methods design, case-study, action research, field survey, experimental, descriptive, exploratory, correlational, longitudinal, comparative studies, etc.;

- by the content analyzed: Initial training program's structure and IE curricula-theoretical instruction on IE and/or field opportunities (direct interaction and/or teaching experiences with students with various disabilities); different variables related to pre-service teachers (beliefs, experiences, attitudes, knowledge, preparation, motivation, concerns, efficacy, teaching skills, or combinations of these topics) in connection with inclusion/IE or the impact of teacher training on these aspects; the use of technology in IE, teacher educators' attitudes/reflections/challenges related to IE; the validation of research tools in the field of IE, partnerships in IE, etc.;

- by the participants involved: Studies that involve regular school pre-service teachers at different levels of their training (the size of the sample between 1 and 2014 participants), studies that involved besides regular school pre-service teachers, special education pre-service teachers/school mentors/teacher educators/students/teaching assistants; studies that involved only teacher educators;

- $\quad$ by the type of experience: Formal and informal experience;

- by the targeted group: Studies focused on specific categories (individuals with hearing impairments, visual impairments, intellectual disabilities, learning disabilities, autism, Down Syndrome, ADHD, physical or motor disabilities, dyslexia; immigrants, ethnic/religious/sexual minorities, etc.) or studies focused on inclusion in general;

- by the level of education for which the pre-service were trained to teach: Early education, primary education, secondary education;

- by specific domains/disciplines involved: Educational Sciences, Physical Education, Mathematics, English, Science, Music, Art, Theater, etc.;

- by the dimension of the investigation: Local, national, or international studies/projects. 
Because the titles, abstracts, and keywords did not allow the accurate identification of these criteria in the case of each document, we could not generate valid statistics. We will limit ourselves to pointing out that these studies included evidence from different regions of the world about the efforts being made in the context of various initial teacher education programs to support the future teachers in becoming inclusive practitioners.

\subsection{RQ2: What Are the Most Influential Journals, Authors, and Papers in ITEIE?}

The research papers were published in 217 source titles (journals, books, or conference volumes). The articles in ITEIE were published in various journals, with different impact factor (IF). Used as a tool for the evaluation and ranking of the scientific journals, IF of a journal is calculated by dividing the number of current year citations to the number of articles published in that journal during the previous two years. The higher the impact factor, the greater the scientific impact of a journal. We referred to the IF for 2018, which was indicated by Journal Citation Report available in WoS at the time when this study was conducted.

Table 2 presents the leading 10 journals in terms of number of published articles in the ITEIE field. Of the 10 identified, 8 journals have an impact factor between 0.818 and 2.411. The International Journal of Inclusive Education published 57 articles, which highlights the great contribution in the expansion and development of ITEIE studies. The next two journals, Teaching and Teacher Education and Teacher Education and Special Education, were ranked in the second and third places with publication of 24 articles and 16 articles, respectively. The articles published in these three journals represent $22.04 \%$ of all of documents in the ITEIE database. The Australian Journal of Teacher Education and Journal of Research in Special Educational Needs are included in the Emerging Sources Citation Index (ESCI). These journals include high-quality, peer reviewed publications, but do not receive Impact Factors. Instead, citations from the ESCI contribute to the impact factors of other journals. Indexing provides a mark of quality and increases the journals' visibility. Most of the top journals publishing on ITEIE were from the Education \& Educational Research category. Other subject categories covered were Special Education and Social Sciences.

In order to determine the productivity of the sources, Bradford's bibliometric law was applied. Using this law has confirmed that a small group of sources provides a high number of documents. A similar finding was revealed in a study on Big Data in education, too [36]. In the context of our analysis, 8 sources ( $3.86 \%$ ) include 148 documents (33.63\%). This is the core zone. In the first zone, 45 sources include the same number of documents as the core zone. The second zone, including 164 sources, collects 144 documents $(32.72 \%)$. In the core zone, the first source International Journal of Inclusive Education published 57 papers, which represents more than one-third of the total articles from the core zone (38.51\%).

Table 2. The top 10 journals that include ITEIE documents indexed in WoS.

\begin{tabular}{lcccc}
\hline \multicolumn{1}{c}{ Journals } & Papers & \% & IF (2018) & $\begin{array}{c}\text { WoS } \\
\text { Category }\end{array}$ \\
\hline International Journal of Inclusive Education & 57 & $12.95 \%$ & 1.053 & EER \\
Teaching and Teacher Education & 24 & $5.45 \%$ & 2.411 & EER \\
Teacher Education and Special Education & 16 & $3.63 \%$ & 0.884 & EER \\
International Journal of Disability Development and Education & 12 & $2.72 \%$ & 0.818 & ES \\
Journal of Research in Special Educational Needs & 12 & $2.72 \%$ & - & SS, ES \\
European Journal of Special Needs Education & 10 & $2.27 \%$ & 1.039 & ES \\
Journal of Education for Teaching & 9 & $2.04 \%$ & 1.373 & EER \\
Asia Pacific Journal of Teacher Education & 8 & $1.81 \%$ & 0.903 & EER \\
Australian Journal of Teacher Education & 8 & $1.81 \%$ & - & SS, ES \\
European Physical Education Review & 8 & $1.81 \%$ & 2.0 & EER \\
\hline
\end{tabular}


Regarding the annual citation patterns, we discovered that the 440 documents have been cited 3581 times since 1999 (Figure 5). Citation distribution shows that citation number increased over time. The average number of citations per item was 8.14 , while the h-index was 27 , which means that there are 27 publications that have received at least 27 citations. Before 2011, few citations were registered, more precisely 198 citations. Starting with 2011, we can see an obvious increase in the number of citations, more precisely from 103 citations (in 2011) to 809 (in 2019). The fact that in 2019 most citations were registered is consistent with most publications being registered in 2019. The lower number of citations in 2020 is due to the fact that for the present study only the citations recorded in the first three months of the year were taken into account.

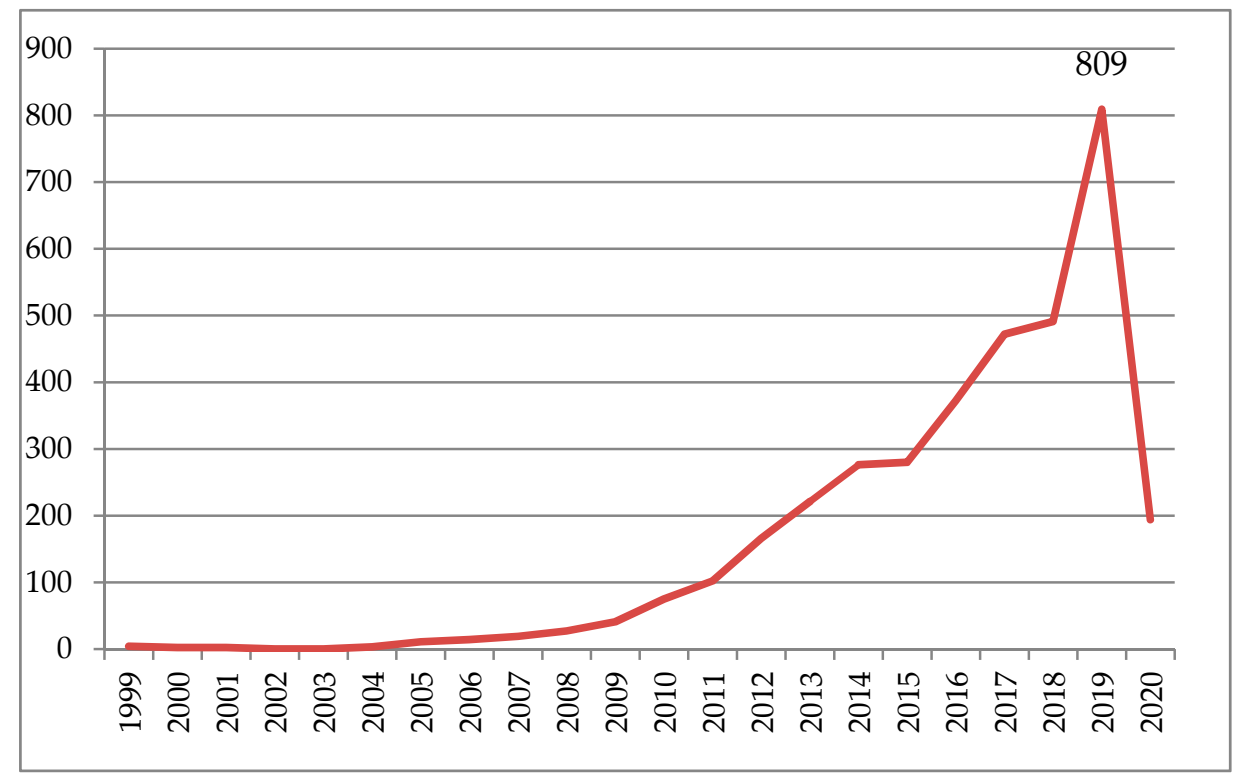

Figure 5. The number of citations of WoS documents on ITEIE field between 1999 and 2020 (7 April).

It is noteworthy, however, that the three types of documents contributed unequally to the amount of citations (Table 3). Thus, out of the total citations registered for the literature on ITEIE, $98.79 \%$ refers to citing articles. Proceedings papers and book chapters are much less cited. These two types of documents together contribute $1.19 \%$ to what citations mean in the ITEIE field. If we compare the three most cited papers in the three types of documents, the difference is huge. While the most impactful article [9] received 172 citations, the most cited proceeding paper [49] collected 7 citations, and the most cited book chapter [50] was found 8 times as a bibliographic reference. $68.38 \%$ of the published articles received citations (with a variation from 1 to 172 citations). Of the 123 articles that did not receive citations, 53.65\% are published in 2019 and 2020. Therefore, these papers are quite new and did not have the necessary time to accumulate citations. It is expected that these works will receive citations in the years to come. In contrast, only $47.05 \%$ of book chapters and only $20.58 \%$ of proceedings papers received citations recorded in WoS. Of those who did not receive citations, one book chapter $(5.88 \%)$ and 7 proceedings papers (20.58\%) were new in the field, namely published in 2019 . The average citation number for articles is 9.1, much higher than the average citation number for book chapters (1.29) or for proceeding papers (0.62). These results prove the articles have a greater weight and impact in scientific literature. 
Table 3. Citation distribution according to the type of documents.

\begin{tabular}{|c|c|c|c|c|c|c|}
\hline $\begin{array}{c}\text { Types of } \\
\text { Documents }\end{array}$ & Number & $\begin{array}{l}\text { Time } \\
\text { Cited }\end{array}$ & h-Index & $\begin{array}{c}\text { Average } \\
\text { Citation/Item }\end{array}$ & $\begin{array}{l}\text { Documents } \\
\text { Cited }\end{array}$ & $\begin{array}{c}\text { Documents } \\
\text { Not Cited }\end{array}$ \\
\hline Articles & 389 & $\begin{array}{c}3538 \\
(98.79 \%) \\
\end{array}$ & 27 & 9.1 & $\begin{array}{c}266 \\
(94.66 \%) \\
\end{array}$ & $\begin{array}{c}123 \\
(77.35 \%)\end{array}$ \\
\hline $\begin{array}{c}\text { Proceedings } \\
\text { papers }\end{array}$ & 34 & $\begin{array}{c}21 \\
(0.58 \%)\end{array}$ & 3 & 0.62 & $\begin{array}{c}7 \\
(2.49 \%) \\
\end{array}$ & $\begin{array}{c}27 \\
(16.98 \%)\end{array}$ \\
\hline $\begin{array}{c}\text { Book } \\
\text { chapters }\end{array}$ & 17 & $\begin{array}{c}22 \\
(0.61 \%)\end{array}$ & 3 & 1.29 & $\begin{array}{c}8 \\
(2.84 \%)\end{array}$ & $\begin{array}{c}9 \\
(5.66 \%)\end{array}$ \\
\hline Total & 440 & 3581 & & & 281 & 159 \\
\hline
\end{tabular}

Next, we used the number of publications and the number of citations as ways to identify the most active and influential researchers in ITEIE. Citations are used as a measure of influence [23]. Almost a thousand authors contributed to the field literature. The analysis of the number of papers and their citations indicates that the most important contributions to the development of the field are made by four researchers, namely Forlin, C., Sharma, U., Loreman, T., and Florian, L. (Table 4). We mention that these authors have more publications indexed on WoS (than those in the table) focused on various aspects of IE, such as: Conceptualizing and assessment of IE, legislation and leadership, policy and practice in special and IE, etc. They are internationally recognized authors, with impressive works, who have made remarkable contributions to the development of IE and who have high values of the Hirsh index in relation to all published work: Sharma $(\mathrm{h}=16 ; 55$ documents, time cited $=1128)$, Forlin $(\mathrm{h}=20$, 69 documents, time cited $=1576)$, Loreman $(h=13,29$ documents, time cited $=820)$, Florian $(h=15$, 47 documents, time cited $=1036$ ). We specify that a researcher has an h-index, if $\mathrm{h} / \mathrm{she}$ has at least $\mathrm{h}$ publications for which he/she has received at least $\mathrm{h}$ citations. For the present study, however, only those papers from the educational research area were selected, in which aspects related to IE intersected with the initial teacher education domain. That is why the number of works and implicitly of the citations refers only to a part of the work of these four successful and influential researchers.

Table 4. The most cited ITEIE authors ranked by WoS.

\begin{tabular}{ccccc}
\hline & Authors & Region/Country & Documents & Citation \\
\hline 1 & Forlin, C. & Hong Kong/China & 9 & 551 \\
2 & Sharma, U. & Australia & 12 & 443 \\
3 & Loreman, T. & Canada & 4 & 336 \\
4 & Florian, L. & Scotland & 5 & 320 \\
\hline
\end{tabular}

The most prolific author in the field of ITEIE is Sharma, U. from Monash University (Australia). Interestingly, of all the author's WoS indexed publications, the works on ITEIE field are among the most cited. The most cited author in ITEIE research literature is Forlin, C. (Education University of Hong Kong) who has contributions in education reform for special and inclusive education in the Asia-Pacific region. With a smaller number of papers in the ITEIE field, Loreman, T. (Concordia University of Edmonton, Canada) is among the most cited authors. In fact, the three authors: Sharma, Forlin, and Loreman collaborated in publishing several works. Two of these are among the most cited articles in ITEIE scientific literature [9,51]. Another internationally recognized researcher who is frequently cited in ITEIE field is Florian, L. from the University of Edinburgh, Scotland, known for her work on the concept of inclusive pedagogy. Three of the articles written by this author are among the 10 most cited works in the field, as we can see in the next section for successful works in the field.

Considering the number of works identified on WoS and the number of citations, we can appreciate that there are other authors with interest in the field of ITEIE, but with a lower impact than the four authors mentioned above. We mention a few names: Kennedy, M.J. (USA, 5 papers, 
47 citations), Pecek, M. (Slovenia, 5 papers, 24 citations), Walton, E. (England, 5 papers, 23 citations), Macura-Milavanovic, S. (Serbia, 4 papers, 24 citations), Rusznyak, L. (South Africa, 4 papers, 22 citations), Saloviita, T. (Finland, 4 papers, 28 citations).

Looking at the distribution of documents by authors, the Price's law, according to which half of the publications are produced by the square root of the number of authors [52], does not apply. In our study, 31 authors (the square root of 984) published 141 documents (out of 440), which is less than half.

Due to the fact that $88.40 \%$ of all publications are classified as articles published in journals, we were interested to find out which are the most influential articles on ITEIE literature. Table 5 presents the most cited ITEIE publications on WoS.

Table 5. The most cited ITEIE publications on WoS.

\begin{tabular}{|c|c|c|c|c|c|}
\hline Title & Authors & Journal & Year & Citation & $\begin{array}{l}\text { Citation } \\
\text { per Year }\end{array}$ \\
\hline $\begin{array}{l}\text { Impact of training on pre-service teachers' } \\
\text { attitudes and concerns about inclusive } \\
\text { education and sentiments about persons } \\
\text { with disabilities }\end{array}$ & $\begin{array}{l}\text { Sharma, U; } \\
\text { Forlin, C; } \\
\text { Loreman, T. }\end{array}$ & $\begin{array}{l}\text { Disability \& } \\
\text { Society }\end{array}$ & 2008 & 172 & 13.31 \\
\hline $\begin{array}{l}\text { Changing student teachers' attitudes } \\
\text { towards disability and inclusion }\end{array}$ & $\begin{array}{l}\text { Campbell, J.; } \\
\text { Gilmore, L.; } \\
\text { Cuskelly, M. }\end{array}$ & $\begin{array}{l}\text { Journal of } \\
\text { Intellectual \& } \\
\text { Developmental } \\
\text { Disability }\end{array}$ & 2003 & 157 & 8.78 \\
\hline $\begin{array}{l}\text { Student teachers' attitudes towards the } \\
\text { inclusion of children with special } \\
\text { educational needs in the ordinary school }\end{array}$ & $\begin{array}{l}\text { Avramidis, E; } \\
\text { Bayliss, P; } \\
\text { Burden, R. }\end{array}$ & $\begin{array}{l}\text { Teaching and } \\
\text { Teacher } \\
\text { Education }\end{array}$ & 2000 & 147 & 7.00 \\
\hline $\begin{array}{l}\text { Teacher preparation for inclusive education: } \\
\text { Increasing knowledge but raising concerns }\end{array}$ & $\begin{array}{l}\text { Forlin, C.; } \\
\text { Chambers, D. }\end{array}$ & $\begin{array}{l}\text { Asia-Pacific } \\
\text { Journal of } \\
\text { Teacher } \\
\text { Education }\end{array}$ & 2011 & 125 & 12.50 \\
\hline $\begin{array}{l}\text { Demographic differences in changing } \\
\text { pre-service teachers' attitudes, sentiments, } \\
\text { and concerns about inclusive education }\end{array}$ & $\begin{array}{l}\text { Forlin, C.; } \\
\text { Loreman, T.; } \\
\text { Sharma, U.; et al. }\end{array}$ & $\begin{array}{l}\text { International } \\
\text { Journal of } \\
\text { Inclusive } \\
\text { Education }\end{array}$ & 2009 & 111 & 9.25 \\
\hline $\begin{array}{l}\text { Preparing teachers for inclusive education: } \\
\text { Using inclusive pedagogy to enhance } \\
\text { teaching and learning for all }\end{array}$ & $\begin{array}{l}\text { Florian, L.; } \\
\text { Linklater, H. }\end{array}$ & $\begin{array}{l}\text { Cambridge } \\
\text { Journal of } \\
\text { Education }\end{array}$ & 2010 & 93 & 8.55 \\
\hline $\begin{array}{l}\text { The inclusive practice project in Scotland: } \\
\text { Teacher education for inclusive education }\end{array}$ & $\begin{array}{l}\text { Florian, L.; } \\
\text { Rouse, M. }\end{array}$ & $\begin{array}{l}\text { Teaching and } \\
\text { Teacher } \\
\text { Education }\end{array}$ & 2009 & 92 & 7.67 \\
\hline $\begin{array}{l}\text { Are preservice teachers prepared to teach } \\
\text { struggling readers? }\end{array}$ & $\begin{array}{l}\text { Washburn, E. K.; } \\
\text { Joshi, R.M.; } \\
\text { Cantrell, E.B. }\end{array}$ & $\begin{array}{l}\text { Annals of } \\
\text { Dyslexia }\end{array}$ & 2011 & 67 & 6.70 \\
\hline $\begin{array}{l}\text { Preparing Teachers to Work in Inclusive } \\
\text { Classrooms: Key Lessons for the } \\
\text { Professional Development of Teacher } \\
\text { Educators from Scotland's Inclusive } \\
\text { Practice Project }\end{array}$ & Florian, L. & $\begin{array}{l}\text { Journal of } \\
\text { Teacher } \\
\text { Education }\end{array}$ & 2012 & 66 & 7.33 \\
\hline $\begin{array}{l}\text { Efficacy beliefs, background variables, } \\
\text { and differentiated instruction of Israeli } \\
\text { prospective teachers }\end{array}$ & $\begin{array}{l}\text { Wertheim, C.; } \\
\text { Leyser, Y. }\end{array}$ & $\begin{array}{l}\text { Journal of } \\
\text { Educational } \\
\text { Research }\end{array}$ & 2002 & 66 & 3.47 \\
\hline
\end{tabular}


These 10 most influential papers were published between 2000-2012 in 9 journals and received $30.22 \%$ of the total number of citations. Two of the most cited papers are published in the same journal, namely Teaching and Teacher Education. Four of the 10 papers have in common that they addressed the pre-service teachers' attitudes about IE/disability/inclusion of children with special educational needs in the ordinary school, as an effect of training $[9,51,53,54]$. Three of these articles are the most cited in the field. The most cited article is co-authored by researchers from different countries: Sharma, Forlin, and Loreman [9], and was published in Disability \& Society journal (IF =1.613), that is not in the top of the journals with most articles on ITEIE field. Working with an international sample of pre-service teachers, the authors presented the effects of training in IE on attitudes towards inclusion, sentiments about people with disabilities, and concerns about inclusion [9]. In a previous study of 2003, which is the second most cited, Campbell, Gilmore, and Cuskelly demonstrated the value of combining theoretical instruction with structured fieldwork experiences in changing pre-service teachers' attitudes towards disability and inclusion [53]. Based on a survey, positive attitudes of pre-service teachers towards the inclusion of children with special needs in ordinary schools, but also problems with their perceived competence were reported in the paper co-authored by Avramidis, Bayliss, and Burden [54].

The concerns of the future teachers about inclusion or about having students with disabilities in their classes were also addressed by the researchers in three papers $[9,15,51]$. Other topics addressed in these most cited papers were: The pre-service teachers' knowledge about legislation and policy related to inclusion [15], about Down Syndrome [53], or about dyslexia [55]; curricular approaches to preparing prospective teachers to develop inclusive practices [20,56,57]; the prospective teachers' efficacy beliefs and choices of differentiated instructional strategies for effective teaching in inclusive classrooms [58]. Two articles present results using international samples of pre-service teachers [9,51], while the other papers present local initiatives undertaken within different university-based initial training programs for the teaching profession. A common feature of these articles is that they are the result of collaboration among authors (both nationally and internationally). Only one work is an exception, being signed by a single author [57].

\subsection{RQ3: What Are the Collaboration Patterns in ITEIE and the Connections Existing between Authors, Journals, and Terms?}

\subsubsection{Co-Authorship: Authors and Countries}

Collaboration is an important feature of modern research. The level of collaboration is an indicator for the state of the art research in a scientific field [59]. Technology facilitates this collaboration and brings together researchers from various fields, countries, and institutions. Using VOSviewer software, we performed a co-authorship analysis in order to identify patterns of collaboration among authors and among countries. The value added by VOSviewer analysis is that we can easily visualize the relationships and networks existing among researchers and countries in ITEIE studies.

We started the analysis with co-authorship on authors. Analyzing ITEIE publications extracted from WoS database, 984 authors who published 440 papers were identified. As we could also see in the WoS analysis, at a threshold of minimum 5 documents per author, there are 6 authors who meet this condition: Sharma, Forlin, Florian, Walton, Kennedy, and Pecek. In this analysis framework (minimum 5 documents per author), only 2 authors have collaborated on this topic: Sharma and Forlin. There are 4 publications they have co-authored. Lowering the threshold to 2 documents per author, out of 984 authors, 86 meet the requirement, but only 10 items are connected. That means that only 10 authors, with at least 2 documents each, collaborated in producing scientific papers in the field of ITEIE (Figure 6). 


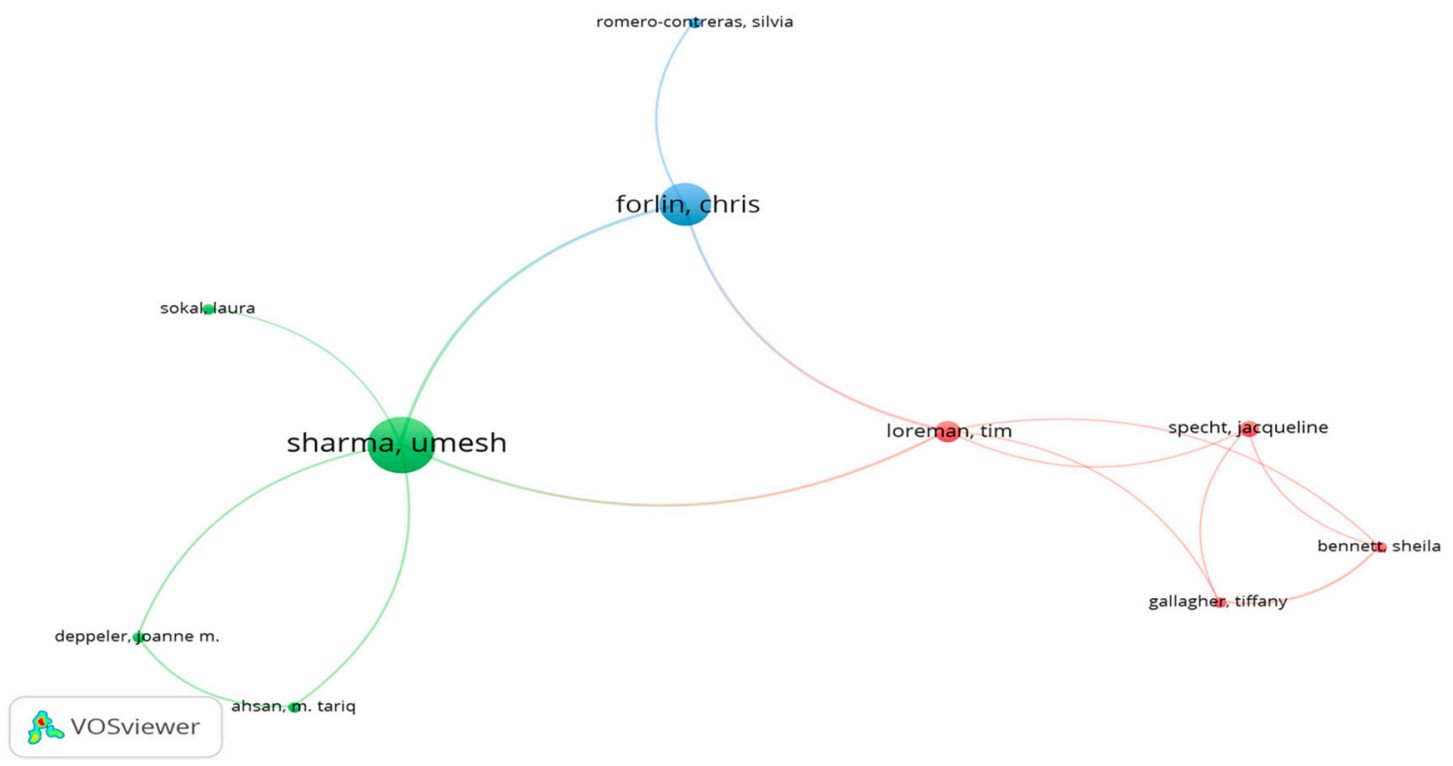

Figure 6. Network of co-authorship (minimum number of documents for each author, 2). Only authors that are connected.

In Figure 6, the nodes represent the author and the size of the nodes the number of documents. The link represents the relation of co-authorship between two authors and offers information about the number of papers they wrote together. The 10 items are organized in 3 clusters, which are built around the most significant author. The first and the second cluster (red and green) contain 4 items or authors each, and the third cluster (blue) has only 2 items. We have 3 groups of authors that collaborated to some papers. One leaded by Sharma (12 papers, 12 co-authorship relations: 4 with Forlin, 3 with Loreman, 2 with Ahsan, 2 with Deppeler, and 1 with Sokal), one leaded by Forlin (9 documents, 9 co-authorship relations: 4 with Sharma, 3 with Loreman, and 2 with Romero-Contreras), and the last one led by Loreman, which has 4 documents, and 9 co-authorship relations. Our analysis shows a strong collaboration between Sharma, Forlin, and Loreman, but they are engaged in co-authorship relations with other researchers, too. If we are looking at the most cited author, Forlin (551 citations), we can see that this author has a strong collaboration with Sharma, the author with the most documents on ITEIE. They produced 4 papers in collaboration.

Co-authorship analysis on countries shows us that collaboration is quite low in ITEIE area at this level. The nodes represent the country and the size of the nodes the number of documents. Out of 65 countries that contributed to those 440 documents, only 29 are connected and are organized in 7 clusters (Figure 7). The largest cluster has 7 items or countries (red). England is a leader in it with 29 documents and 11 co-authored documents. The most prolific collaboration is with Sweden (3 papers in collaboration), and then with Norway (2 papers). The second cluster (green) has 5 items and is built around Australia with 54 documents and 9 collaborations with different countries, and 18 co-authored papers. The biggest number of papers results from the collaboration with China ( 5 papers) and Canada (4 papers). The third cluster (dark blue) contains 5 items, and is led by the USA with 140 documents, 10 relations of collaborations, and 20 papers co-authored. The USA has a good collaboration with South Korea and Spain (4 papers with each country). The other clusters are built around Canada, Spain, Russia, and Ireland. Even if USA produced the most papers on ITEIE, the prolific most author is from Australia, which means that a nucleus of research focused on ITEIE has been established in Australia. 


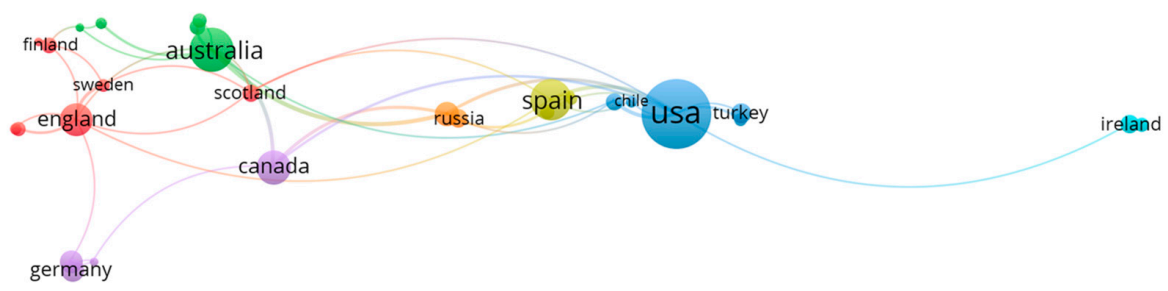

\section{禹 vosviewer}

Figure 7. Network of co-authorship at country level. Out of 65 countries, 39 meet the threshold (minimum number of documents of a country, 2) and 10 countries are not connected.

\subsubsection{Co-Citation Analysis-Cited Authors, and Cited Sources}

In this analysis, the units are cited authors and cited sources. It helps us to see the presence of two items together in the same reference list and offers a map that can reveal the "intellectual structure" of our domain of interest, using similarities among researchers $[46,60,61]$. What is very important in co-citation analysis is the fact that it brings together papers which are outside the WoS index, too. It offers a larger view on the influences that exist at scientific community level. The most significant assumption of co-citation analysis is that the more two items are cited together, the more likely it is that their content is related [23].

We started the analysis with the authors' co-citation. Four clusters resulted: First cluster with 21 authors (red), the second with 14 authors (green), the third with 13 authors (blue), and the fourth with 4 authors (yellow) (Figure 8). The nodes represent the number of citations. The most cited authors are in the green cluster. Forlin is cited along with other 50 authors 3225 times (total link strength). As it can be seen, Sharma is cited along with other 49 authors 2961 times (total link strength). The red cluster is led by Florian, who is cited together with 50 authors 1333 times. The other two clusters, the blue one, led by Darling-Hammond, and the yellow one, led by Lancaster.

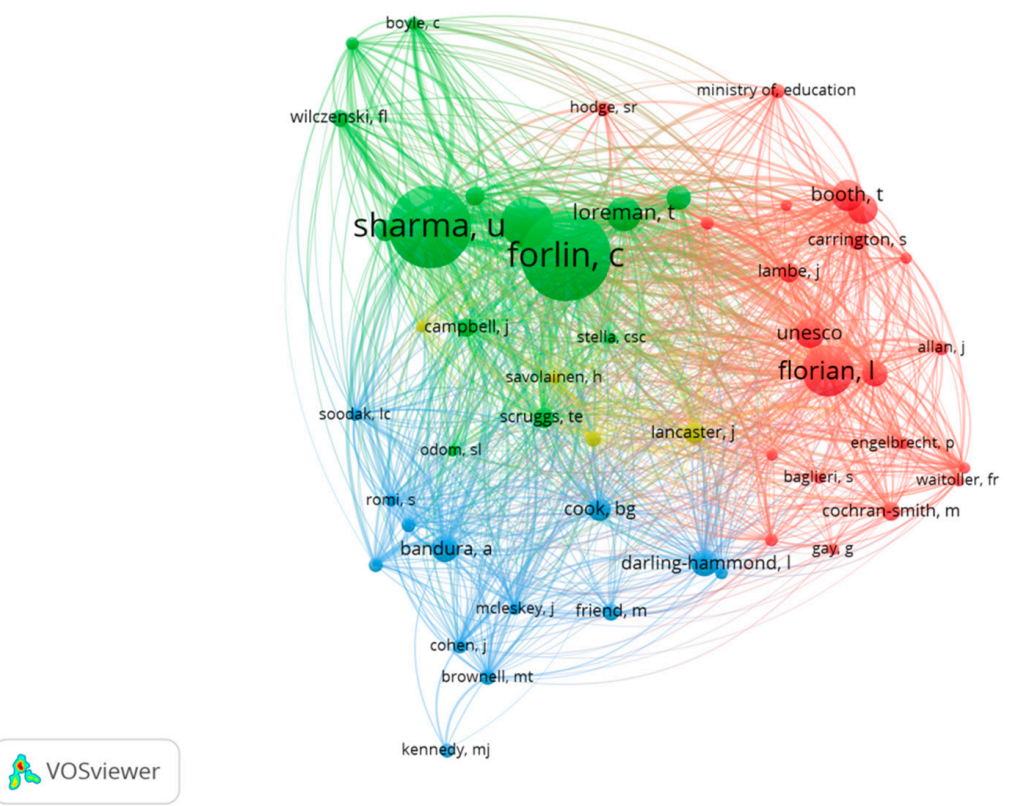

Figure 8. Network of co-citations-cited authors. Out of 9401 authors, 52 meet the threshold (minimum number of citations per author: 20). 
If we are looking at the items in the red cluster, we can see that Florian appears in co-citation most frequently with UNESCO and Slee. We can see from Figure 8 that the closer the items, the stronger the relationship. If some authors appear frequently together, it means that their research interests and the topics they address are similar. The authors that appear the most frequently in the same reference list are Forlin and Sharma, with 638 co-citation relationships. Then, Forlin appears with Avramidis 240 times. Forlin and Loreman appear in co-citation 190 times.

The results of the cited sources co-citation analysis are 4 clusters, which bring together 47 journals (Figure 9). The size of the node represents the number of citations of the journal. The first cluster, the red one, has 20 items or sources, and is organized around the International Journal of Inclusive Education, the most cited sources which appears together with another 46 journals of 7740 times. The International Journal of Inclusive Education holds the first position in the occurrence of direct citations, too. The European Journal of Special Needs Education is another important source in this cluster and is cited along with other sources 3685 times. It appears most frequently cited by the International Journal of Inclusive Education (491 times). The Journal of Research in Special Educational Need and Disability and Society are two other journals which occur together in the reference list with the International Journal of Inclusive Education (486 times and 378 times, respectively). That means that the contents of these journals are quite related and have an important influence in ITEIE. Teacher Education and Special Education journal appears most frequently cited with Exceptional Children (325 link strength). The strongest relation is between the International Journal of Inclusive Education and Teaching and Teacher Education (910 co-citations relationships). These sources are the two first journals in the top 10 journals that include ITEIE-related documents, indexed in WoS.

The second cluster is the green one with 12 items led by the Journal of Teacher Education cited along with other sources 2762 times. The third cluster (blue) contains 10 items and is built around Teacher Education and Special Education, the main journal that is cited along with 46 other sources 4109 times. The yellow cluster (5 items) has an important journal, Teaching and Teacher Education, with 46 co-citation relations and 7326 occurrences.

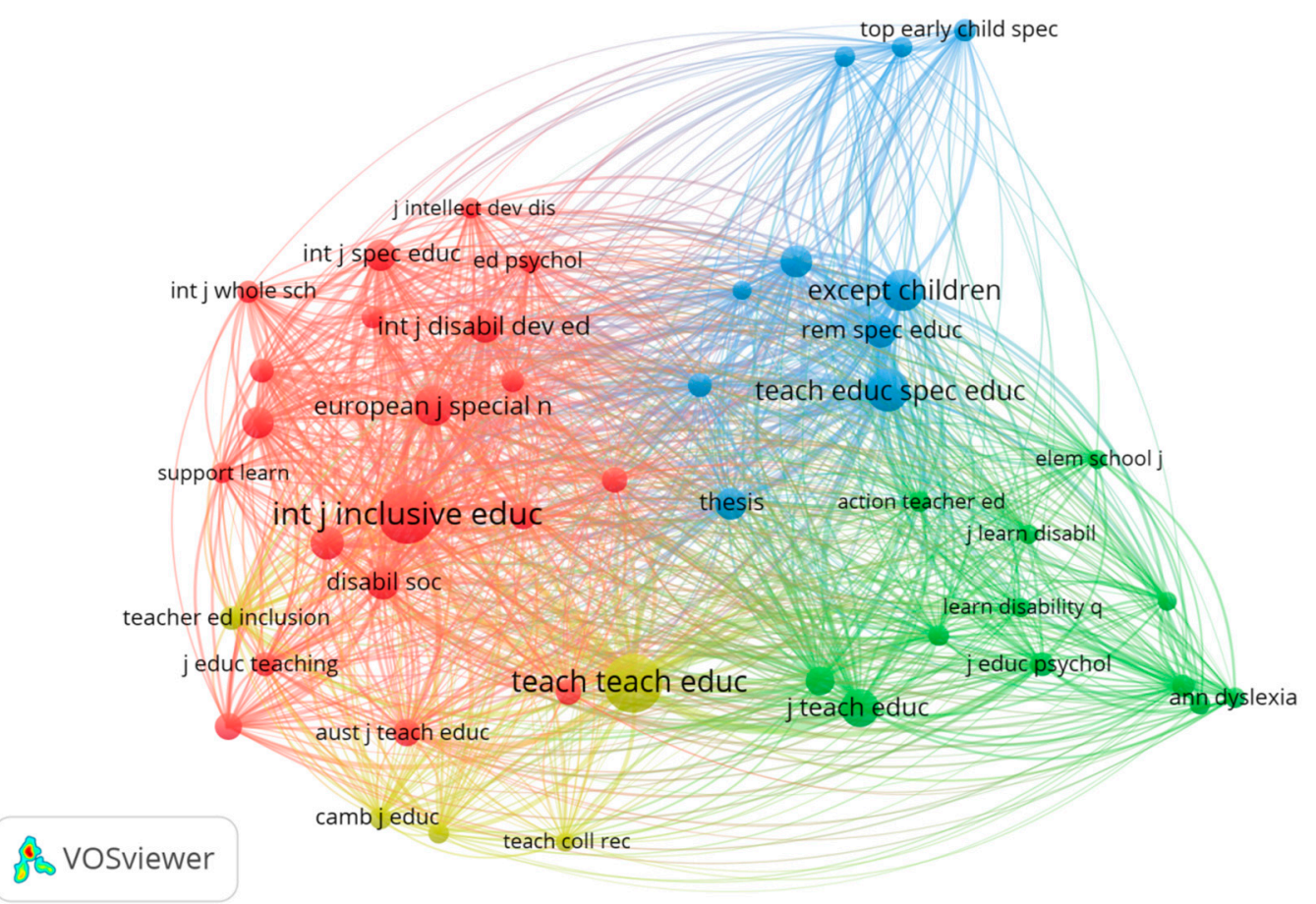

Figure 9. Sources that occur in co-citation. Out of 7016 cited sources, 47 meet the threshold (minimum number of citations of a cited source: 40 ). 


\subsubsection{Co-Occurrence of Keywords and Terms Analysis}

Co-occurrence of keywords and terms means to identify the keywords and terms that are found together in the same paper. This analysis shows a relationship among these co-occurring keywords and terms in a network map [23,46]. Two thesaurus files were used to match the words that were spelled differently in keywords list, title, or abstract (e.g., preservice/pre-service, programme/program) or plural/singular (e.g., attitudes/attitude, disabilities/disability).

This analysis helps us to see the main topics which researchers are interested in, to build a conceptual map. Additionally, it can highlight the major trends in research in ITEIE. We started the analysis focusing on the authors' keywords, and using VOSviewer software, the papers in which two keywords appears together are counted. Starting from the 440 ITEIE documents, 907 keywords were identified. Only keywords with a minimum of 5 occurrences were included, that means 42 keywords. Six clusters were created, and each cluster contains related keywords that appear with the same color (Figure 10). The most relevant keywords are represented by the largest nodes. The size of the node represents the number of occurrences. For each cluster there is a keyword, an item, which occurs most frequently: "Inclusive education" (red cluster-10 items), "inclusion" (green cluster-9 items), "preservice teacher education" (dark blue cluster -7 items), "attitudes" (yellow cluster-7 items), "pre-service teachers" (purple cluster -6 items), "teacher education" (light blue cluster-3 items).

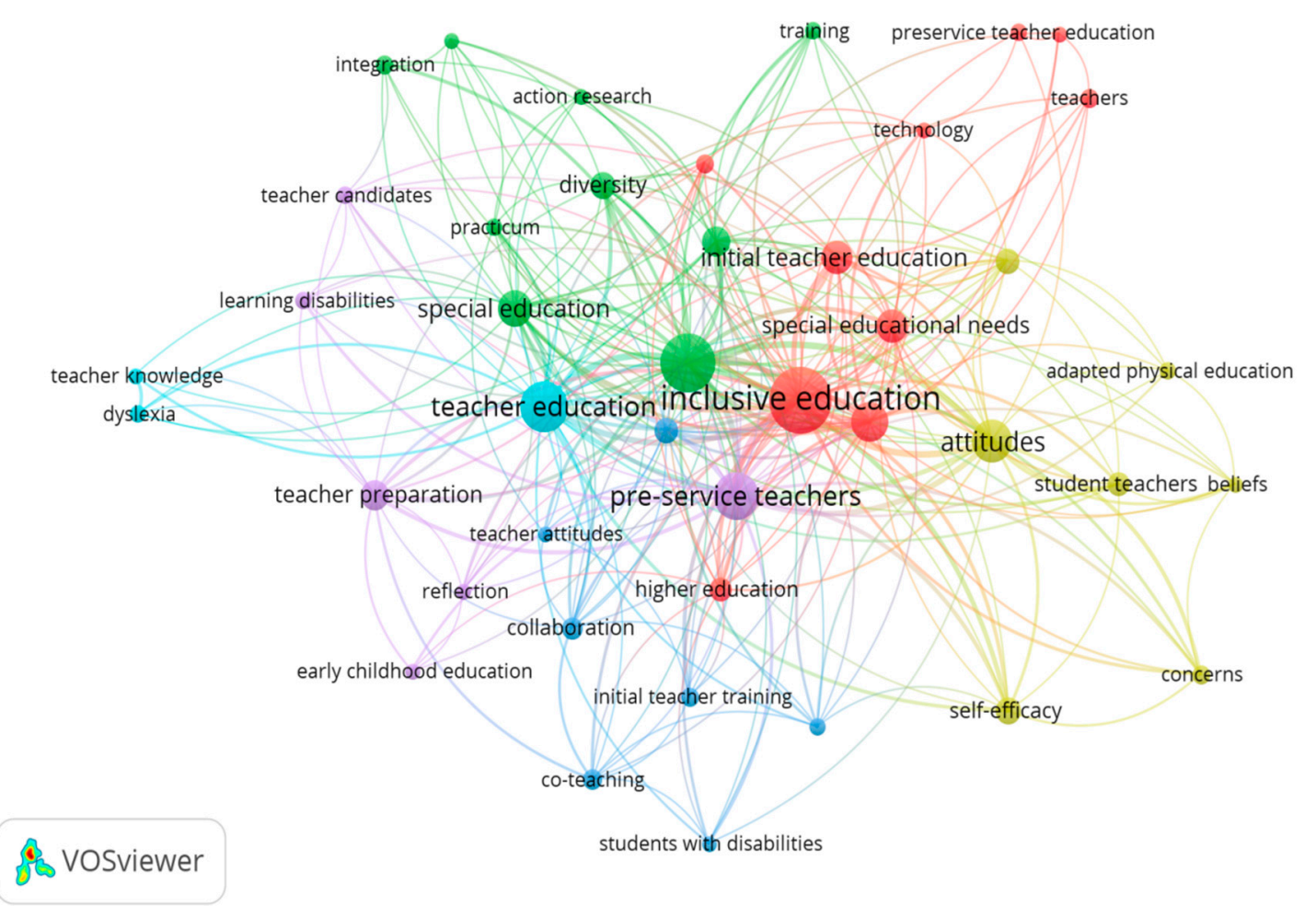

Figure 10. Co-occurrence of author keywords. Of the 907 keywords, 41 meet the threshold (minimum number of occurrences of a keyword: 5).

The most common keyword is "inclusive education" with 126 occurrences and appears together with another 32 keywords 192 times. Then comes "inclusion" with 93 occurrences and appears together with 37 keywords 178 times, and "teacher education' with 70 occurrences and appears together with 29 keywords 130 times. "Inclusive education" and "inclusion" appear most frequently with "attitude", "pre-service teachers", and "teacher education". These concepts are the essence of the conceptual map on ITEIE.

A co-word analysis focused on terms appearing in title and abstract helped us to identify 7641 terms, but only 93 meet the relevance score (Figure 11). The 93 terms were organized in 4 large clusters. 
The first cluster (red) contains 31 items and highlights the most recurrent words "learning", "program", "preservice teacher", "instruction preparation", "reflection". The second cluster (green) has 22 items and brings together terms like "special education needs", "student teacher", "work", "activity". The blue cluster has 22 items, too, and is built around words like "attitude", "implication", "self-efficacy", "scale". The yellow cluster has 18 items, and the most common are "development", "process", "diversity", "person", "questionnaire". These terms are the key concept of the conceptual map resulted from the co-occurrence of terms analysis.

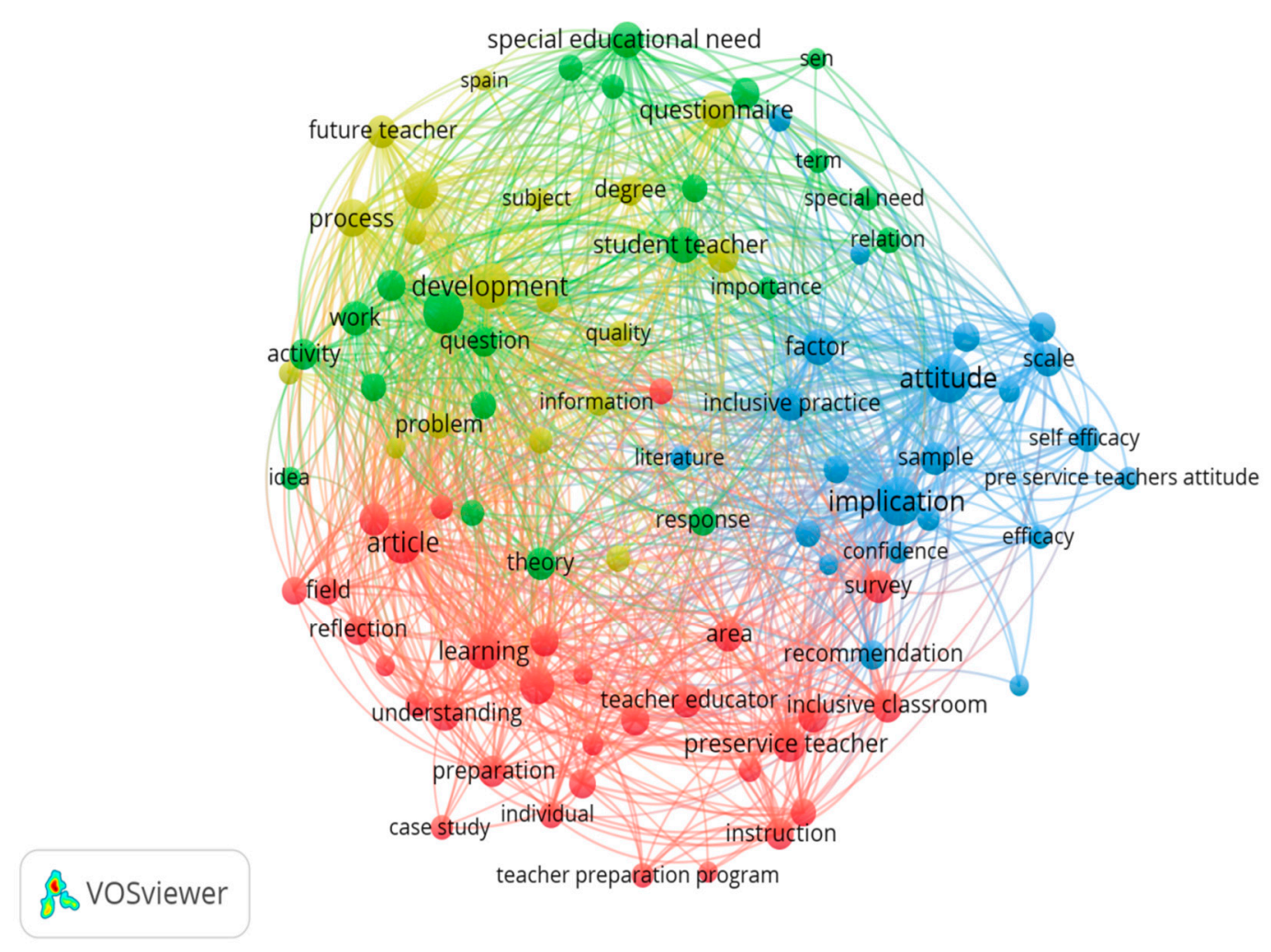

Figure 11. Network of co-occurring terms in title and abstract. Out of 7641, 156 meet the threshold (minimum number of occurrences: 15), 93 meet the relevance score.

The size of the nodes represents the number of occurrences of a term. If we organize the common concepts in themes, the next themes emerge: The pre-service teachers' learning about IE in the context of teacher training programs; pre-service teachers' activity/response related to special education needs); examining the different variables in pre-service teachers (attitudes, efficacy, confidence, etc.) in terms of IE; the professional development of pre-service teachers on IE.

\section{Discussion}

This study performed a systematic analysis on ITEIE research literature, in the area of Education and Educational Research, using bibliometric analysis of 440 indexed documents in WoS database. We observed its evolution over time (between 1996 and 7 April 2020), and the contributions from different countries and organizations. We also identified types of documents that fueled the evolution of the field, the most relevant journals, authors, and papers that brought a significant contribution to the development of ITEIE, the networks created among the authors and countries, respectively, and the connections between authors, sources, and terms.

We could see a progressive increase in the interest of researchers in ITEIE field, an aspect confirmed by the growing number of published papers over the decades. If in 1996 the first two works in the field were identified, in 2019 the most works were registered $(n=74)$. However, it is only since 2008 that a more noticeable increase in the number of works has occurred. Since 2015, this upward trend 
has become even more evident. Based on annual publication patterns, three stages of development of the field were identified: An early stage with few publications (1996-2007), a moderate growth stage (2008-2014), and a high growth stage (2015-2020). Two thirds of the total number of works was published during the last stage. The momentum gained by the concept of IE [18] supported by international or national policies over time, the progress and the challenges in preparing future teachers for implementing inclusive practices, and the wide range of journals in which researchers can publish works in educational and educational research area are factors that may account for the increase in the number of published works over the years. We estimate that the production of literature on ITEIE will continue to grow in the next years.

IE is a global issue, and research on it has been carried out in many countries around the world. However, the United States of America (USA) is by far the leading country in producing knowledge and research on the ITEIE filed. Other contributing countries are: Australia, Spain, Canada, and England. These five developed countries have produced almost $70 \%$ of the total publications. These results can be explained by the fact that in these countries there are productive universities, with high research capacity and a constant publication policy in the field of ITEIE. This is the case of Monash University (Australia), which is the most prolific organization in the field, of University of Virginia, California State University, University of North Carolina etc. (USA), of University of Valencia and University of Córdoba (Spain), etc. Our findings regarding the leading countries were consistent with those reported by Hernández-Torrano and colleagues [31] and by Shah and colleagues [32], although their study focused on IE in general.

Most ITEIE publications are authored by researchers located in a few countries. This unbalanced distribution across the globe, with low research productivity from developing countries was also reported in a bibliometric review of research on higher education for sustainable development [60]. The authors of this study emphasized the need for formal research funding programs designed to stimulate research in developing societies [60]. In this respect, we would like to add that the increasing visibility on WoS of the contributions in ITEIE from all over the world would be helpful.

Following the analysis of the types of documents and the languages in which they are written, two major ideas emerged: For researchers in ITEIE, the articles are the main means to communicate the scientific information; English is the most used language for writing and communicating the research results in the field. This is related to the fact that in WoS, English-language journals are favored to the detriment of other languages [44]. The most consistent contribution to the development of the ITEIE field is brought by articles, not only by their obviously much higher number compared to other types of documents, but also by the number of citations received. In our study, we found that an impressive $98.79 \%$ of the citations recorded for ITEIE literature come from citing articles. The articles are much more cited than proceeding papers and book chapters, which is an additional argument for the impact they have in the research area. An increasing trend toward citation was found over time, which is a positive and encouraging signal for the development of scientific literature in ITEIE.

The analysis of the journals showed that literature in the field of ITEIE was published in diverse journals, mainly from Education and Educational Research category, but also from Special Education and Social Science. The International Journal of Inclusive Education, which is recognized as a prestigious journal in the field of inclusive/special education [62], has published most papers in the field of ITEIE. This journal was also identified as the main host for IE research in two other bibliometric studies, one from 2020, where the analysis was performed on the Scopus database on the issue of IE in general [31], and one published in 2017, which used WoS, Scopus, and Google scholars for searching IE research [32]. Other journals with the most publications in ITEIE, such as Teaching and Teacher Education, the International Journal of Disability Development and Education, the European Journal of Special Needs Education, and the Journal of Research in Special Educational Needs, were also reported among those in the tops publishing on IE [31,32]. IE's strong roots in special education, the interrelated history of these two concepts [63] can explain the fact that some of the works in the field of IE are published in journals in the field of special education. However, most WoS indexed journals, featuring ITEIE topics 
belong to Education and Educational Research category and focus on teacher education. This is an important aspect for the development of the field, which does not exclude a necessary co-existence between special and IE [63].

The analysis of the number of papers and their citations showed us that the most important contributions to the development of the field are brought by 4 researchers: Forlin, Sharma, Loreman, and Florian. These key authors and their documents have shaped the evolution of literature in ITTIE. Again, our results are consistent with the findings by the previous bibliometric studies on IE [31,32]. These four authors are listed as top authors by number of publications in the field of IE, presented in the cited studies. They have a long-term consistent interest in the field of IE. Both in our study and in that of Hernandez and colleagues [31], Sharma was found as the most prolific author and one of the most cited in the literature in the field of ITEIE and IE respectively. However, there are also differences in the results concerning authors in the two studies. For instance, Pijl, S.J. (Netherland) and Carrington, S. (Australia) are top of the list with the most works in IE [31]. Nevertheless, they haven't made it to the top in this paper, because although both authors have rich expertise in the field of IE, as confirmed by the large number of publications including on WoS (46 and 39, respectively), their work was not primarily focused on training teachers for inclusive practices, but in other subdomains of IE.

As concerns the most influential 10 publications on ITEIE by the number of citations, we noticed a direct connection between the four most prolific authors mentioned above and the importance of their works. Many of the top-cited publications were authored by these four researchers. In the top, Forlin and Florian appear with three publications, and Sharma and Loreman with two publications. Two of the most cited works are the result of collaboration between three of the four authors: Sharma, Forlin, and Loreman [9,51]. These three authors seem to form a consolidated research group with high impact in the field. Nine of the ten most cited papers are the result of collaboration between researchers, which indicates the functionality and productivity of research groups in the field. One of the most common topics addressed in these papers is the pre-service teachers' attitudes towards inclusion. In their review, Launtenbach and Heyder [41] also reported that improving attitudes to inclusion in pre-service teachers is a topic of interest in research and teacher education practice. Other topics addressed in the most frequently cited works are the pre-service teachers' concerns about IE, their knowledge about inclusion/disability, the curricular approach to prepare prospective teachers to work in inclusive classroom, etc.

The results regarding the most influential works and their type differ from those presented in the bibliometric study conducted by Hernández-Torrano and colleagues [31]. We keep referring to it because it is the most recent study published and it seems closer to the present study by topic, but not by the database used, which was Scopus. None of the works included in the top of the most cited papers in ITTIE was found in the top of most influential publications, made by Hernández-Torrano and colleagues [31]. In their study, the ten most cited articles address topics such as: Teachers' attitudes towards IE, inclusive learning environments, pupils with special education needs' views and experience in inclusive settings, inclusive schooling, co-teaching in the inclusive classroom, the effectiveness of IE. Around half of these are reviews on general issues in IE [31], which is quite different from our study, where most of the influential publications are empirical studies. It is true that we excluded review documents from our study (but they were very few anyway and received very few citations). These differences can come mainly from two sources: (a) The use of two different databases (Wos and Scopus, respectively); (b) this study is on ITEIE-focused research literature (which is only a line of research of IE), while the other one deals with the IE global research literature, which is a much broader field. The finding that ITEIE papers are not among the most influential in the IE field does not indicate a lack of interest from researchers in this line of research (Figure 2 clearly showed the opposite), but rather it mirrors a certain prioritization of the important topics in the field. The fact that IE is a relatively new concept may explain the large number of citations received by the papers, usually theoretical in nature, in which the authors make clarifications in the field or present conceptual discussions. Furthermore, the more frequent citation of studies in the area of in-service teacher training 
may reflect the urgent need to provide answers to the many challenges that teachers face directly in their work on a daily basis on the one hand, and to meet the needs of all students in regular classes, on the other hand. We see here opportunities for further research and bibliometric investigations on literature focusing on in-service teacher education for IE.

An interesting finding that brings us closer to the study of Hernández-Torrano and colleagues [31] is that the topic of the attitude towards IE is the most frequently investigated topic of all the most cited papers in ITEIE and in IE, respectively. Given the importance of the IE, the attitude of the pre-service teachers as well as of experienced teachers towards IE seems to be a topic of great interest to researchers.

Co-authorship analysis points to the fact that ITEIE is an emergent field of study with poor collaboration among authors and countries. Most papers are written in the same country or institution. Strong cooperation among countries with interest in ITEIE is not fostered. Even if the USA produced most of the papers on ITEIE, the most prolific author comes from Australia. Additionally, there is no co-authorship between the USA and Australia or between the USA and England. Australia collaborates frequently with China, and the USA with South Korea.

As concerns collaboration among authors, the situation is not very different. Of 86 authors who published at least 2 papers, only ten are connected and are engaged in scientific production together. These are also the most influential authors focusing on ITEIE: Sharma, Forlin, Florian, and Loreman. Hernández-Torrano has also noticed Sharma and Forlin's shared interest in their studies on school and teachers [31]. The fact that 76 authors did not collaborate points to the lack of an international structural support network for researchers in common issue investigations. Hence, the need to develop more cross-border research groups whose joined scientific production is more likely to influence the development of ITEIE.

The co-citation analysis reveals the connections existing between cited authors and cited journals. The authors cited in the same paper who appear frequently together suggest common research interests. The results reflect the direct citation analysis. The authors that are cited most frequently in the same paper are Forlin and Sharma, with 638 co-citations. Then, Forlin and Avramidis are cited in 240 papers. Forlin and Loreman appear together in 190 co-citations. A new author who has joined the "classics" in ITEIE is Avramidis, a researcher interested in teachers' attitude toward inclusion, who has become a respected professional in this field with a literature review paper [64]. This finding confirms the idea that the attitude toward inclusion is of topic interest to researchers focusing on initial teacher education as well as continuous teacher education.

In the co-citation analysis on cited sources, the International Journal of Inclusive Education holds the first position. This journal is also in the top in terms of direct citation. The European Journal of Special Needs Education, the Journal of Research in Special Educational Need, and Disability E Society are sources that appear very often in the same reference list as the International Journal of Inclusive Education. The strongest relation is between the International Journal of Inclusive Education and Teaching and Teacher Education (910 co-citations), the first two journals in top 10 journals that include ITEIE-related documents, indexed in WoS. This confirms the influence of these journals on ITEIE.

Keyword analysis offers a conceptual map of the research on ITEIE. "Inclusive education" and "Inclusion" are concepts that are frequently associated with "attitude", "pre-service teachers", and "teacher education". If we look at the authors' keywords, these concepts lie at the heart of ITEIE-related research. This map is completed with the analysis of co-occurrences of terms in titles and abstracts. The conceptual structure resulted reveals some topics of interest for IE researchers: The pre-service teachers' learning about IE; the pre-service teachers' actions related to special education needs; the study of some important variables such as attitudes, efficacy, confidence, etc. in relation to IE; the professional development of pre-service teachers on IE. "Inclusive education" is missing from the conceptual structure resulted from terms analysis. It is replaced by "inclusive practice", "inclusive classroom". "Implication", "attitude", and "development" are in the top of occurrences in title and abstract. A wide diversity of concepts and a variety of term combinations can be noticed. Whereas keywords such as "inclusive education" and "inclusion" stand out more than others, in the 
case of terms we cannot talk about a consolidated structure at concept level. Researchers use a variety of terms. This can be explained by the different educational approaches depending on regional or national policies.

The literature on ITEIE mainly reflects the calibration of different university-based teacher education programs on the requirements of IE, in terms of policy, curriculum development, and practices. The most numerous are empirical studies, focusing on preparing future teachers for teaching, interacting, or providing different types of support to/with students with special educational needs or disabilities in inclusive environments. This emphasis on certain special educational needs or particular categories has also been noted in other studies $[8,40,62]$ and mirrors a restrictive way of relating to the concept of IE, which we talked about in the introductory part of this paper. Messiou considers that such an approach is in contradiction to the principles of IE-if inclusion demands a focus on all learners, then research in IE should focus on all children [62]. For this to happen, the author argues in favor of a collaborative approach to research that encourages the active involvement of participants throughout the various stages of the research, which will generate a direct impact on them [62]. This is an interesting approach, but also a challenging one. The future will confirm whether researchers in the field will be prepared for a shift from an approach focused on various categories of special educational needs to forms of investigations which include everyone and which foster the collaborative work of both researchers and participants.

Most studies that focused on interventions on pre-service teachers' perceptions, attitudes, knowledge, and teaching strategies related to IE highlighted positive effects on future teachers. Such positive effects on pre-service teachers were also noted in a review made on a smaller sample of studies in the field [43]. However, these results must be viewed with caution. The transition of the pre-service teachers to the phase of novice teachers can bring changes in terms of attitudes, knowledge, and self-efficacy concerning inclusion, in the sense of dropping them, as a recent study warns [65]. Changes associated with the transition from teacher preparation program to the first two years of teaching in terms of teaching efficacy were also identified in the study led by Thomson and colleagues [66]. Hence, the need to conduct more longitudinal studies on the dynamics of competencies related to inclusion that integrate different stages of teacher professional development.

We found that IE is embedded in different teacher education programs through various disciplines. Besides the Sciences of Education disciplines, one of the disciplines best represented in ITEIE studies is Physical Education, which shows an increased interest of researchers in this field. The presence of the European Physical Education Review in the top 10 journals that include ITEIE related documents strengthens this finding.

\section{Conclusions}

This study examined the scientific research in ITEIE between 1996 and 2020 (7 April), based on publications in the WoS database. Findings revealed that: The number of publications has increased over the time; most publications in the field are authored by researchers located in a few countries; the articles are the main means to communicate the scientific information and the most cited compared with other types of documents; ITEIE is an emergent field of study with poor collaboration among authors and countries; the pre-service teachers' learning about IE, their attitudes, efficacy, or confidence concerning IE are topics of interest for the researchers in the field.

The analyses performed provide insights into the development of the ITEIE research and can be valuable sources of information for university program managers and teacher educators, PhD students working with this literature. By mapping the evolution of ITEIE literature from its beginnings in the mid-1990s to the present without subjective bias, this study can help and guide scholars towards a better understanding of the structure and dynamics of the field while minimizing time and effort. Researchers interested in developing structured literature reviews in the field can find useful information in this paper. 
In conclusion, through its procedures and the results, our study can be described as complementary to other previous bibliometric studies in the field of IE, to which we referred throughout this paper. At the same time, our study draws attention to a line of research in IE, namely the training of future teachers, which has not been explored so far from a bibliometric perspective.

\subsection{Limitations and Future Work}

As the results of bibliometric analyses may vary depending on the database used [44], one limitation of this study might be that some relevant papers could have been excluded, namely those that were not indexed on WoS. Perhaps an integrated approach of more databases (Scopus, Elsevier Science Direct, Google Scholar, etc.) which also assure an expanded sample size, can help to obtain a more comprehensive picture in the field. Another limitation may be related to the restriction of research to the three types of documents indexed in WoS (articles, conference papers, and book chapters) and the exclusion of other types of documents such as reviews, editorial materials, and abstract meetings. However, given that their number was very small, we do not believe that it would have influenced the results of this research significantly.

The scholars interested in the field can continue our work. Our data can serve as an input for other bibliometric studies, which can explore, for instance, the relationship between the in-service teacher training and IE, or between both pre- and in-service teacher education and IE. One area that seems little explored through research refers to the preparation of future university professors for academic inclusion. Diversity is not only found in kindergartens and schools. The university teachers also face a diverse student population. Those who will teach in higher education also need training in IE. How are future teachers prepared to address diversity and to promote inclusive practices in teaching and learning in higher education? This is a topic less researched that is worth to be addressed in future studies. In the future, researchers will definitely have to focus more on ITEIE-related issues at all educational levels.

\subsection{Theoretical and Practical Implications}

Through our work, we bring more visibility to the efforts that teacher educators from different countries of the world have made to empower future teachers to respond to the diverse needs of learners. Through their vision and practices, future teachers play a key role in building a more inclusive and sustainable society, in which each individual is valued. How they will manage to be well prepared to understand and embrace diversity, to develop inclusive learning environments, or to address various forms of exclusion or marginalization in educational settings, is an open and challenging issue likely to generate new research in the field. If the research in ITTIE grows and moves forward, it would also be interesting to observe its dynamics and evolution through subsequent bibliometric approaches. By providing an overview of research in the field of ITEIE, by highlighting the contributions of countries, journals, authors, and the collaboration patterns in the field, by opening new perspectives for future research, this work contributes both theoretically and practically to the scientific community.

Author Contributions: Conceptualization, D.M.C. and F.M.; methodology, D.M.C. and F.M.; validation, D.M.C. and F.M.; formal analysis, D.M.C. and F.M.; investigation, D.M.C.; data curation, D.M.C. and F.M.; writing-original draft preparation, D.M.C. and F.M.; writing-review and editing, D.M.C. and F.M.; visualization, D.M.C. and F.M.; supervision, D.M.C.; project administration, D.M.C. All authors have read and agreed to the published version of the manuscript.

Funding: This research received no external funding.

Conflicts of Interest: The authors declare no conflict of interest. 


\section{References}

1. Walton, E.; Rusznyak, L. Choices in the Design of Inclusive Education Courses for Pre-service Teachers: The Case of a South African University. Int. J. Disabil. Dev. Educ. 2016, 64, 231-248. [CrossRef]

2. United Nations Educational, Scientific and Cultural Organization. The Salamanca Statement and Framework for Action on Special Needs Education; UNESCO Publishing: Paris, France, 1994. Available online: https: //unesdoc.unesco.org/ark:/48223/pf0000098427 (accessed on 20 April 2020).

3. United Nations Educational, Scientific and Cultural Organization. United Nations Convention on the Rights of Persons with Disabilities; United Nations Publishing: New York, NY, USA, 2006. Available online: https: //www.un.org/disabilities/documents/convention/convention_accessible_pdf.pdf (accessed on 20 April 2020).

4. United Nations Educational, Scientific and Cultural Organization. Inclusive Education: The Way of the Future. Conclusions and Recommendations of the 48 the Session of the International Conference on Education; United Nations Publishing: Geneva, Switzerland, 2008. Available online: https://unesdoc.unesco.org/ark: /48223/pf0000180629 (accessed on 20 April 2020).

5. United Nations. Transforming Our World: The 2030 Agenda for Sustainable Development: A/RES/70/1; UN: New York, NY, USA, 2015. Available online: https://sustainabledevelopment.un.org/content/documents/21 252030\%20Agenda\%20for\%20Sustainable\%20Development\%20web.pdf (accessed on 20 April 2020).

6. United Nations Educational, Scientific and Cultural Organization. Education 2030 Incheon Declaration and Framework for Action; United Nations Publishing: Incheon, Korea, 2015. Available online: https: //unesdoc.unesco.org/ark:/48223/pf0000245656 (accessed on 20 April 2020).

7. Ainscow, M.; Slee, R.; Best, M. Editorial: The Salamanca Statement: 25 years on. Int. J. Incl. Educ. 2019, 23, 671-676. [CrossRef]

8. Amor, A.M.; Hagiwara, M.; Shogren, K.A.; Thompson, J.R.; Verdugo, M.A.; Burke, K.M.; Aguayo, V. International perspectives and trends in research on inclusive education: A systematic review. Int. J. Incl. Educ. 2018, 23, 1277-1295. [CrossRef]

9. Sharma, U.; Forlin, C.; Loreman, T. Impact of training on pre-service teachers' attitudes and concerns about inclusive education and sentiments about persons with disabilities. Disabil. Soc. 2008, 23, 773-785. [CrossRef]

10. United Nations Educational, Scientific and Cultural Organization. A Guide for Ensuring Inclusion and Equity in Education; UNESCO: Paris, France, 2017. Available online: https://unesdoc.unesco.org/ark: /48223/pf0000248254 (accessed on 20 April 2020).

11. Göransson, K.; Nilholm, C. Conceptual diversities and empirical shortcomings-A critical analysis of research on inclusive education. Eur. J. Spéc. Needs Educ. 2014, 29, 265-280. [CrossRef]

12. Nilholm, C.; Göransson, K. What is meant by inclusion? An analysis of European and North American journal articles with high impact. Eur. J. Spéc. Needs Educ. 2017, 32, 437-451. [CrossRef]

13. Krischler, M.; Powell, J.J.W.; Cate, I.M.P.-T. What is meant by inclusion? On the effects of different definitions on attitudes toward inclusive education. Eur. J. Spéc. Needs Educ. 2019, 34, 632-648. [CrossRef]

14. Magnússon, G. An amalgam of ideals-images of inclusion in the Salamanca Statement. Int. J. Incl. Educ. 2019, 23, 677-690. [CrossRef]

15. Forlin, C.; Chambers, D. Teacher preparation for inclusive education: Increasing knowledge but raising concerns. Asia Pac. J. Teach. Educ. 2011, 39, 17-32. [CrossRef]

16. Coates, J.K.; Harris, J.; Waring, M. The effectiveness of a special school experience for improving preservice teachers' efficacy to teach children with special educational needs and disabilities. Br. Educ. Res. J. 2020. [CrossRef]

17. Walton, E.; Rusznyak, L. Cumulative knowledge-building for inclusive education in initial teacher education. Eur. J. Teach. Educ. 2019, 43, 18-37. [CrossRef]

18. Florian, L. Preparing teachers to work in 'schools for all'. Teach. Teach. Educ. 2009, 25, 533-534. [CrossRef]

19. Florian, L.; Camedda, D. Enhancing teacher education for inclusion. Eur. J. Teach. Educ. 2019, 43, 4-8. [CrossRef]

20. Florian, L.; Rouse, M. The inclusive practice project in Scotland: Teacher education for inclusive education. Teach. Teach. Educ. 2009, 25, 594-601. [CrossRef]

21. Merigó, J.M.; Yang, J.B. Accounting Research: A Bibliometric Analysis. Aust. Account. Rev. 2016, 27, 71-100. [CrossRef] 
22. Grosseck, G.; Tîru, L.G.; Bran, R.A. Education for Sustainable Development: Evolution and Perspectives: A Bibliometric Review of Research, 1992-2018. Sustainability 2019, 11, 6136. [CrossRef]

23. Zupic, I.; Čater, T. Bibliometric Methods in Management and Organization. Organ. Res. Methods 2014, 18, 429-472. [CrossRef]

24. Yllmaz, R.M.; Topu, F.B.; Tulgar, A.T. An examination of the studies on foreign language teaching in pre-school education: A bibliometric mapping analysis. Comput. Assist. Lang. Learn. 2019, 1-24. [CrossRef]

25. Hulme, M.; Wood, J.; Shi, X. Measuring up? Metrics and research assessment in UK teacher education. J. Educ. Teach. 2020, 46, 220-239. [CrossRef]

26. Cretu, D.M. An analysis of teacher education research in the Web of Science. J. Plus Educ. 2019, 24, 31-38.

27. Çiftçi, Ş.K.; Danışman, Ş.; Yalçın, M.; Tosuntas, S.B.; Ay, Y.; Sölpük, N.; Karadağ, E. Map of Scientific Publication in the field of Educational Sciences and Teacher Education in Turkey: A Bibliometric Study. Educ. Sci. Theory Pract. 2016, 16, 1097-1123. [CrossRef]

28. Song, Y.; Chen, X.L.; Hao, T.Y.; Liu, Z.N.; Lan, Z.X. Exploring two decades of research on classroom dialogue by using bibliometric analysis. Comput. Educ. 2019, 137, 12-31. [CrossRef]

29. Rodríguez-García, A.M.; Torres, J.M.T.; Rodríguez, J.S. Impacto de la productividad científica sobre competencia digital de los futuros docentes: Aproximación bibliométrica en Scopus y Web of Science. Rev. Complut. Educ. 2019, 30, 623-646. [CrossRef]

30. Viseu, J.N.; De Jesus, S.N.; Quevedo-Blasco, R.; Rus, C.L.; Canavarro, J.M. Motivação docente: Estudo bibliométrico da relação com variáveis individuais, organizacionais e atitudes laborais. Rev. Latinoam. de Psicol. 2015, 47, 58-65. [CrossRef]

31. Hernández-Torrano, D.; Somerton, M.I.; Helmer, J. Mapping research on inclusive education since Salamanca Statement: A bibliometric review of the literature over 25 years. Int. J. Incl. Educ. 2020, 1-20. [CrossRef]

32. Shah, S.R.U.; Mahmood, K.; Hameed, A.D. Review of Google scholar, Web of Science, and Scopus search results: The case of inclusive education research. Libr. Philos. Pract. 2017. Available online: https: //digitalcommons.unl.edu/cgi/viewcontent.cgi?article=4419\&context=libphilprac (accessed on 20 April 2020).

33. Lantaron, B.S.; Medialdea, A.L. Research on inclusive education: Production of works in Spanish journals and doctoral thesis. Rev. Educ. Inclusiva 2018, 11, 151-174.

34. Castro, A.M.P.; Garcia, M.J.M.; Perez, E.M.G. Bibliometric study of scientific production doctoral thesis in Inclusive Education. In Proceedings of the 9th International Conference on Education and New Learning Technologies (EDULEARN), Barcelona, Spain, 3-5 July 2017; pp. 10291-10296.

35. Esteve, M.I.V.; Suelves, D.M.; Chacón, J.P.; Baldoví, M.I.P. Technologies for attention to diversity: A bibliometric study. In Proceedings of the 5th International Conference on Higher Education Advances (HEAd'19), Valencia, Spain, 26-28 June 2019; pp. 973-981. [CrossRef]

36. Marín-Marín, J.-A.; Belmonte, J.L.; Fernández-Campoy, J.-M.; Romero-Rodríguez, J.-M. Big Data in Education. A Bibliometric Review. Soc. Sci. 2019, 8, 223. [CrossRef]

37. Tristani, L.; Bassett-Gunter, R. Making the grade: Teacher training for inclusive education: A systematic review. J. Res. Spéc. Educ. Needs 2019. [CrossRef]

38. Symeonidou, S. Initial teacher education for inclusion: A review of the literature. Disabil. Soc. 2017, 32, 401-422. [CrossRef]

39. Boon, H. What do ADHD Neuroimaging Studies Reveal for Teachers, Teacher Educators and Inclusive Education? Child Youth Care Forum 2020, 1-29. [CrossRef]

40. Quintero, J.; Baldiris, S.; Rubira, R.; Cerón, J.; Velez, G. Augmented Reality in Educational Inclusion. A Systematic Review on the Last Decade. Front. Psychol. 2019, 10, 1835. [CrossRef] [PubMed]

41. Lautenbach, F.; Heyder, A. Changing attitudes to inclusion in preservice teacher education: A systematic review. Educ. Res. 2019, 61, 231-253. [CrossRef]

42. McNeil, S.; Lante, K.; Pill, S. A review of the literature on inclusive pedagogy in physical education 2005-2015. Learn. Communities Int. J. Learn. Soc. Context. 2017, 21, 74-94. [CrossRef]

43. Kurniawati, F.; De Boer, A.A.; Minnaert, A.; Mangunsong, F. Characteristics of primary teacher training programmes on inclusion: A literature focus. Educ. Res. 2014, 56, 310-326. [CrossRef]

44. Mongeon, P.; Paul-Hus, A. The journal coverage of Web of Science and Scopus: A comparative analysis. Science 2015, 106, 213-228. [CrossRef]

45. Moher, D.; Liberati, A.; Tetzlaff, J.; Altman, U.G. Preferred Reporting Items for Systematic Reviews and Meta-Analyses: The PRISMA Statement. PLoS Med. 2009, 6, e1000097. [CrossRef] 
46. van Eck, N.J.; Waltman, L. Visualizing Bibliometric Networks. In Measuring Scholarly Impact: Methods and Practice; Ding, Y., Rousseau, R., Wolfram, D., Eds.; Springer: Dordrecht, The Netherlands, 2014; pp. 285-320.

47. Van Eck, N.J.; Waltman, L. Software survey: VOSviewer, a computer program for bibliometric mapping. Scientometrics 2009, 84, 523-538. [CrossRef]

48. Price, D.J. Little Science, Big Science. and Beyond; Columbia University Press: New York, NY, USA, 1986.

49. Jelas, Z.M. Learner Diversity and Inclusive Education: A New Paradigm for Teacher Education in Malaysia. In International Conference on Learner Diversity 2010; Jelas, Z.M., Salleh, A., Azman, N., Eds.; Elsevier Procedia: Bangi, Malaysia, 2010; Volume 7, pp. 201-204.

50. Copfer, S.; Specht, J. Measuring effective teacher preparation for inclusion. In Measuring Inclusive Education; Forlin, C., Loreman, T., Eds.; Emerald: Bingley, UK, 2014; Volume 3, pp. 93-113.

51. Forlin, C.; Loreman, T.; Sharma, U.; Earle, C. Demographic differences in changing pre-service teachers' attitudes, sentiments and concerns about inclusive education. Int. J. Incl. Educ. 2009, 13, 195-209. [CrossRef]

52. Sengupta, I.N. Bibliometrics, Informetrics, Scientometrics and Librametrics: An Overview. Libri 1992, 42, 75-98. [CrossRef]

53. Campbell, J.; Gilmore, L.; Cuskelly, M. Changing student teachers' attitudes towards disability and inclusion. J. Intellect. Dev. Disabil. 2003, 28, 369-379. [CrossRef]

54. Avramidis, E.; Bayliss, P.; Burden, R. Student teachers' attitudes towards the inclusion of children with special educational needs in the ordinary school. Teach. Teach. Educ. 2000, 16, 277-293. [CrossRef]

55. Washburn, E.K.; Joshi, R.M.; Cantrell, E.B. Are preservice teachers prepared to teach struggling readers? Ann. Dyslexia 2010, 61, 21-43. [CrossRef] [PubMed]

56. Florian, L.; Linklater, H. Preparing teachers for inclusive education: Using inclusive pedagogy to enhance teaching and learning for all. Camb. J. Educ. 2010, 40, 369-386. [CrossRef]

57. Florian, L. Preparing Teachers to Work in Inclusive Classrooms: Key Lessons for the Professional Development of Teacher Educators from Scotland's Inclusive Practice Project. J. Teach. Educ. 2012, 63, 275-285. [CrossRef]

58. Wertheim, C.; Leyser, Y. Efficacy Beliefs, Background Variables, and Differentiated Instruction of Israeli Prospective Teachers. J. Educ. Res. 2002, 96, 54-63. [CrossRef]

59. Reyes-Gonzalez, L.; Gonzalez-Brambila, C.N.; Veloso, F. Using co-authorship and citation analysis to identify research groups: A new way to assess performance. Scientometrics 2016, 108, 1171-1191. [CrossRef]

60. Hallinger, P.; Chatpinyakoop, C. A Bibliometric Review of Research on Higher Education for Sustainable Development, 1998-2018. Sustainability 2019, 11, 2401. [CrossRef]

61. Gmür, M. Co-citation analysis and the search for invisible colleges: A methodological evaluation. Scientometrics 2003, 57, 27-57. [CrossRef]

62. Messiou, K. Research in the field of inclusive education: Time for a rethink? Int. J. Incl. Educ. 2016, 21, 146-159. [CrossRef]

63. Florian, L. On the necessary co-existence of special and inclusive education. Int. J. Incl. Educ. 2019, 23, 691-704. [CrossRef]

64. Avramidis, E.; Norwich, B. Teachers' attitudes towards integration / inclusion: A review of the literature. Eur. J. Speéc. Needs Educ. 2002, 17, 129-147. [CrossRef]

65. Mintz, J.; Hick, P.; Solomon, Y.; Matziari, A.; Ó’Murchú, F.; Hall, K.; Cahill, K.; Curtin, C.; Anders, J.; Margariti, D. The reality of reality shock for inclusion: How does teacher attitude, perceived knowledge and self-efficacy in relation to effective inclusion in the classroom change from the pre-service to novice teacher year? Teach. Teach. Educ. 2020, 91, 103042. [CrossRef]

66. Thomson, M.M.; Walkowiak, T.A.; Whitehead, A.N.; Huggins, E. Mathematics teaching efficacy and developmental trajectories: A mixed-methods investigation of novice K-5 teachers. Teach. Teach. Educ. 2020, 87, 102953. [CrossRef]

(C) 2020 by the authors. Licensee MDPI, Basel, Switzerland. This article is an open access article distributed under the terms and conditions of the Creative Commons Attribution (CC BY) license (http://creativecommons.org/licenses/by/4.0/). 